\title{
Sicher vor Dämonen? \\ Musikarchäologische \\ Forschungen zu Glocken \\ in awarischen Gräbern
}

\author{
Beate Maria Pomberger \\ Peter Stadler
}

\begin{abstract}
Zusammenfassung
Aus dem Awarenreich sind einige wenige Glockenfunde bekannt, die jedoch nicht weiter erforscht sind. Um Aufschluss über ihre Funktion und Bedeutung zu erhalten, wurden in einer Pilotstudie fünf Bronzeglöckchen aus dem spätawarischen Mädchengrab 157, Vösendorf-Laxenburger Straße, Niederösterreich, auf Tonhöhe, Schallpegel und Reichweite akustisch untersucht. Die Grundtöne der beiden größeren und eines der drei kleinen Glöckchen ergaben einen Dreiklang, welcher durch das vierte gemessene kleine Glöckchen durch eine Sekund gestört wurde. Der Schallpegel der Glöckchen ist gering, ihre Reichweite geht nicht über 0,5 m hinaus. Die im zweiten Teil des Beitrags vorgestellte Glockentypologie zeigt, dass die Formen Großteils antike Wurzeln haben, drei Typen dürften auf östliche Vorgänger zurückgehen. Alle 72 bislang bekannten awarischen Glocken, die aus 40 Fundorten und 63 Fundkontexten stammen, beschränken sich auf Ungarn, Österreich, Serbien und die Slowakei. Zurzeit sind keine Funde aus Rumänien bekannt. Ist in frühawarischer Zeit die größte Anzahl an Glocken in Gebrauch, so nimmt diese in den späteren Epochen rapide ab, was wahrscheinlich darauf zurückzuführen ist, dass Schellen modern werden. Der Vergleich der Glockenfunde aus den 53 Awarengräbern bezüglich ihrer Lage im Grab zeigt, dass sich die meisten Glocken im Becken- und Oberschenkelbereich befanden. Das deutet darauf hin, dass die Idiophone in Behältnissen oder an Ketten bzw. Schnüren am Gürtel getragen wurden. Der Brauch, sich mit Glocken zu schmücken bzw. diese mit sich herumzutragen, dürfte vorwiegend spätantike Wurzeln haben und steht möglicherweise mit apotropäischem Schutz in Verbindung. Innerhalb der Gräber mit Glocken nehmen Frauenbestattungen die erste Stelle ein, gefolgt von Kindern und Männern. Lediglich in einem Grab lag die Glocke beim Pferd. Da in der Regel jedes Grab nur eine Glocke enthielt, nehmen das Mädchengrab 157 aus Vösendorf-Laxenburger Straße mit fünf Bronzeglöckchen, das Männergrab 471 aus Kölked Feketekapu A mit drei Eisenglocken und drei weitere ungarische Gräber mit je zwei Glocken eine Ausnahmestellung ein.
\end{abstract}

\section{Schlüsselbegriffe}

Glocken, apotropäisch, Amulett, Awaren, Gräber, Bestattung, Typologie, Archäoakustik, Musikarchäologie, Frühmittelalter, Ungarn, Slowakei, Serbien, Österreich, Vösendorf-Laxenburger Straße.

\begin{abstract}
Safe from Demons? - Archaeo-Musicological Research on Bells from Avaric Graves
\end{abstract}

Only a few bells are known from the area of the Avar Khaganate and these have not, hitherto, been the subject of serious investigation. In order to gain a better insight into their function and meaning, five bronze bells from a girl's grave dating to the late Avar period (Grave 157, Vösendorf-Laxenburger Straße, Lower Austria) were tested acoustically for pitch, sound level and range. The keynotes of the two larger and one of the three small bells form a triad, whose harmony is disturbed by the fourth bell. The sound level of the bells is low, the range does not exceed $0.5 \mathrm{~m}$. The typology of the bells, discussed in the second part of the study, shows that most of the bells originate in Classical Antiquity and three types may have eastern predecessors. To date, 72 Avar bells have been discovered and these come from 40 localities and 63 contexts (53 graves and 10 stray discoveries) in Hungary, Austria, Serbia, and Slovakia. The authors are not aware of any finds from Romania. The largest number of bells have been found in graves dating to the early Avar period and there seems to have been a rapid decrease in numbers during the Middle and Late Avar periods, perhaps due to the rise in the popularity of pellet bells. In the final section of the study, the position of the bells on the bodies in the 53 Avaric graves is reviewed. Most of the bells were found in the area of the pelvis and the femora, which suggests that they were worn in containers or on chains or strings fastened to the belt. The custom of decorating oneself with bells or of carrying them around on the body can probably be traced back to Late Antiquity and may be associated with apotropaic observances intended to turn away harm or evil influences. Bells are most frequently associated with the graves of women, followed by those of children and men. In one instance a bell was associated with a horse. Since Avaric graves generally contain only a single bell, five instances (the girl's grave from VösendorfLaxenburger Straße with five bronze bells, a male grave from Kölked Feketekapu A with three iron bells, and three further Hungarian graves with two bells each), can be considered exceptional.

\section{Keywords}

Bells, apotropaic, amulet, Avars, graves, burial, typology, archaeoacoustics, music archaeology, Early Middle Ages, Hungary, Slovakia, Serbia, Austria, Vösendorf-Laxenburger Straße. 


\section{Einleitung}

Im Jahre 2001 wurde in der Laxenburger Straße bei Vösendorf, Niederösterreich, ein awarisches Gräberfeld von der archäologischen Abteilung des Österreichischen Bundesdenkmalamtes unter der Leitung von Franz Sauer im Zuge des Baues der S1-Trasse der in einer Rettungsgrabung ausgegraben. Dabei wurden 443 Gräber entdeckt, von denen die frühesten in die späte Periode der awarischen Landnahme (ca. 568-630) datieren. Der Großteil stammt jedoch aus der mittel- und spätawarischen Zeit (ca. 630-822). ${ }^{1}$ Der Fund von fünf Glöckchen im Grab eines kleinen Mädchens gab den Anlass, sich mit Glocken und Glöckchen im awarischen Khaganat eingehender zu beschäftigen, um Aufschluss über deren Funktion und Bedeutung zu erlangen. Wie auch Schellen, treten Glöckchen vorwiegend in Personengräbern auf.

\subsection{Eine Kleinkindbestattung mit fünf Glöckchen, Vösendorf-} Laxenburger Straße

Der hier vorgestellte Befund stammt aus Grab 157, Planum 3. Im NW-SO orientierten Grab wurde ein 4-5-jähriges Kind (Infans I), der Grabausstattung nach zu schließen weiblichen Geschlechts, in einem Holzsarg beerdigt, dessen Seitenwände und obere Wand durch dunkelbraune Verfärbungen im Boden erkennbar waren. Das Skelett ist im Bereich des Oberkörpers, der rechten Beckenschaufel und beider Oberschenkelknochen gut erhalten (Abb. 1). Die restlichen Knochen sind vergangen. Das tote Kind wurde auffallend reich bestattet (Abb. 2). Es trug einen ovalen Ohrring mit Granulationsverzierung am linken Ohr sowie eine Perlenkette mit Mosaikaugenperlen der blauen Gruppe um den Hals. Daneben lagen zwei kugelförmige Blechknöpfe. Am rechten Arm trug das Kind zwei, am linken einen Bronzearmreif sowie an beiden Armen je einen Armreif aus Eisen. Am Hals schmückten zwei vergoldete, dosenförmige Agraffen das Gewand. Zwei weitere kreisrunde mit bunten Glaseinlagen besetzte Agraffen lagen im Fußbereich. Vier Ringe aus dünnem Bronzedraht sowie eine Bronzedrahtspirale befanden sich zur rechten Seite der Füße. Bemerkenswert sind zwei größere und drei Miniaturglöckchen aus Bronze sowie eine schön verzierte Nadelbüchse. All diese Stücke wurden auf der rechten Körperseite oberhalb des Kopfes deponiert. In der rechten unteren Ecke der Grabgrube außerhalb des Sarges befand sich ein Tontopf. ${ }^{2}$ Das Grab datiert in die Stufe Spätawarisch III. ${ }^{3}$

1 SAuer 2007, Gesamtplan. - Zur Anthropologie siehe PanyKucera, WiltschKe-SChrotTa 2017.

2 SAUER 2007, 86-87.

3 Mitteilung Franz Sauer, Bundesdenkmalamt Österreich.

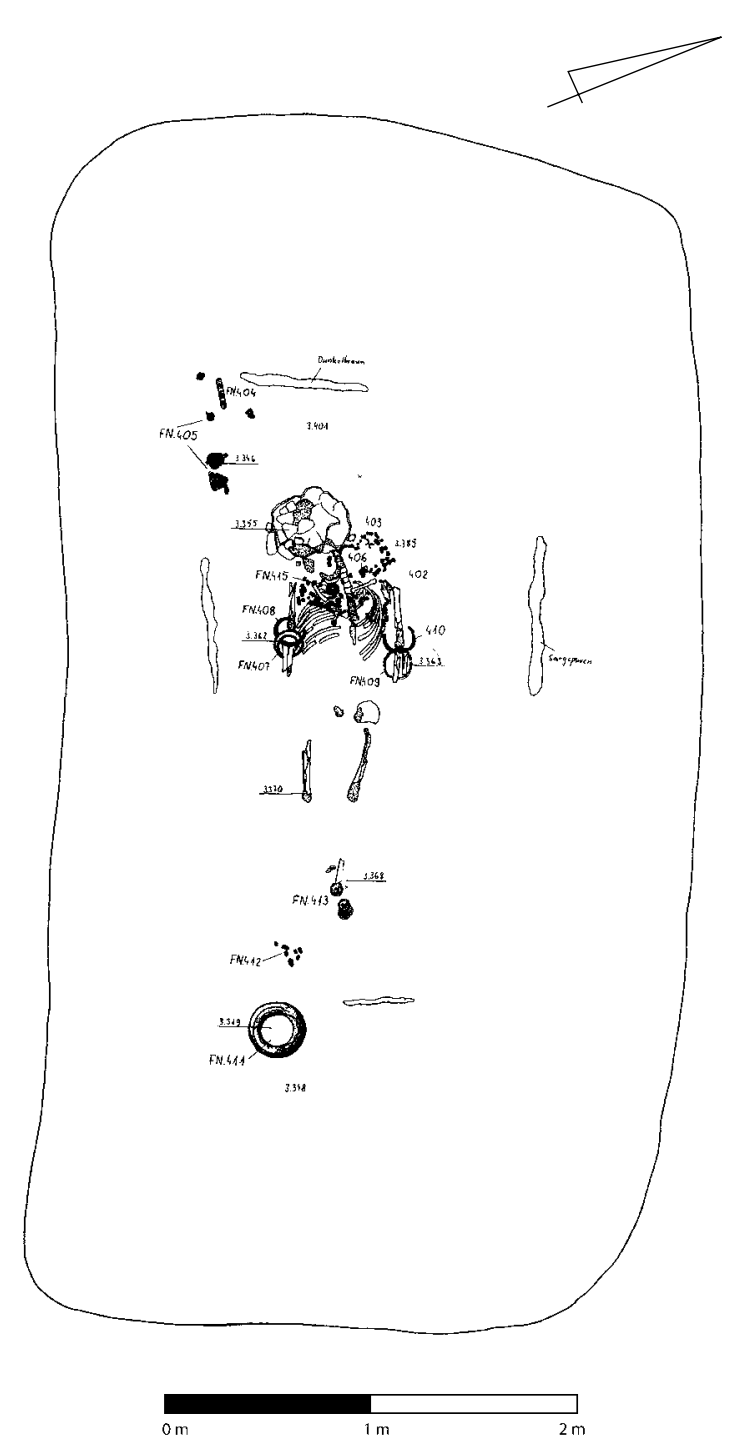

Abb. 1. Grab 157, Vösendorf-Laxenburger Straße. Befund mit Kennzeichnung der Lage der Glocken (Zeichnung: J. M. Czubak, BDA).

\section{Die Glöckchen aus Grab 157, Vösendorf-Laxenburger Straße}

Die fünf gegossenen Bronzeglöckchen besitzen alle kalotten- bzw. kegelförmige Klangkörper mit runden Basen. Glöckchen A, FNr. 405-A, weist eine runde bis eckige Öse auf. Knapp unterhalb des Glockenscheitels befinden sich zwei nachträglich zugefügte Löcher, in die ein kleiner eiserner Ring gesteckt wurde. In diesem hängt ein weiterer kleiner Eisenring, an dem der eigentliche Klöppel befestigt war. Beide Ringe sind an den Bronzemantel ankorrodiert. Der Klöppel selbst fehlt. Knapp unterhalb des Scheitels zeichnet sich eine kleine rechteckig-ovale „Marke“ ab. Die kleine Glocke ist 3,4 cm hoch, hat einen Durchmesser von $4 \mathrm{~cm}$ 


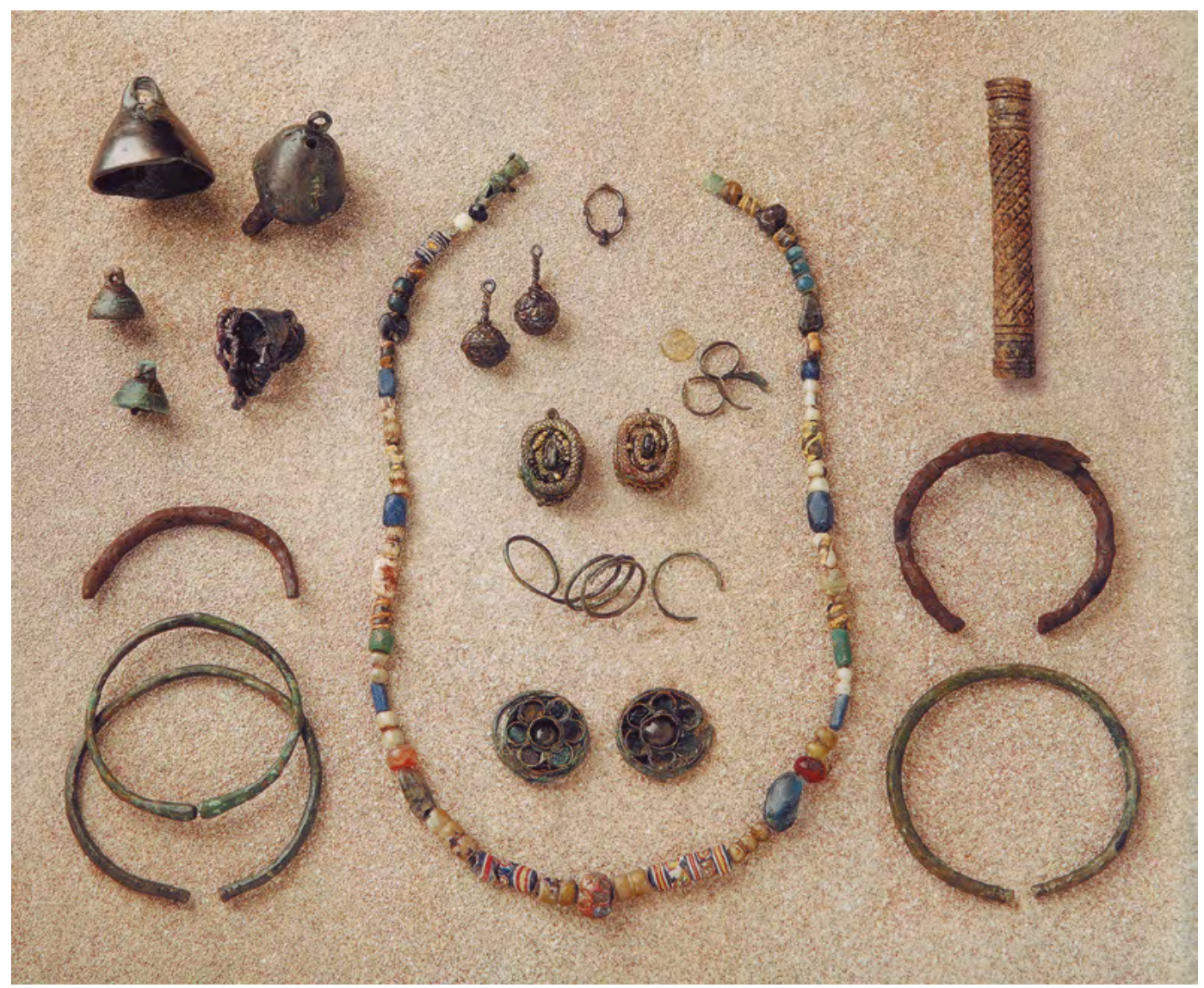

Abb. 2. Grab 157, Vösendorf-Laxenburger Straße. Inventar des Grabes 157 (SAUER 2007, 86).

und eine Wandstärke von $2 \mathrm{~mm}$. Ihr erhaltenes Gewicht beträgt $34 \mathrm{~g}$ (Abb. 3/1; 4/1a-b).

Glöckchen B, FNr. 405-B, ist etwas deformiert. Es weist eine runde, etwas abgehobene Aufhängeöse auf und knapp unterhalb des Scheitels ein länglich-ovales, später erzeugtes großes Loch, dem gegenüber ein weiteres kleines rundes Loch liegt. Der eiserne Klöppel hängt in Originalposition an einem Eisenring. Der Klöppel wurde geschmiedet und ist an die Mantelwand ankorrodiert (Abb. 3/2; 4/2a-b). Die Maße des Instrumentes betragen 3,2 cm in der Höhe, 2,9 $\times$ $3,5 \mathrm{~cm}$ im Durchmesser und $2 \mathrm{~mm}$ in der Wandstärke. Sein erhaltenes Gewicht ist $22 \mathrm{~g}$.

Das Glöckchen C, FNr. 405-C, ist zur Gänze erhalten. Es hat eine rechteckige Aufhängeöse, auf der unteren Hälfte umläuft eine Rille den Resonanzkörper. Sein Eisenklöppel ist vollständig erhalten, haftet aber am Mantelinneren durch Korrosion an. Eine Eisenkette aus acht runden Kettengliedern ist am Manteläußern angerostet (Abb. 3/3;4/3a-b). Die Maße des Glöckchens betragen 1,6 cm in der Höhe, 1,6 cm im Durchmesser, und die Wand weist eine Stärke von $1 \mathrm{~mm}$ auf. Das Idiophon wiegt $11 \mathrm{~g}$. Der Klöppel misst $2 \mathrm{~cm}$ in der Länge, die Schaftdicke $4 \mathrm{~mm}$ und seine Endverdickungen belaufen sich auf $5 \mathrm{~mm}$.

Das Glöckchen D, FNr. 405-D, ähnelt dem vorhin beschriebenen. Lediglich der Eisenklöppel fehlt. Die weggerostete Klöppelöse ist durch zwei Stümpfe am Scheitelinneren der kleinen Glocke lokalisierbar (Abb. 3/4; 4/4a-b, jeweils das rechte Glöckchen). Es ist 1,6 cm hoch, misst im Durchmesser 1,7 mm mit einer Wandstärke von $1 \mathrm{~mm}$. Es bringt lediglich $5 \mathrm{~g}$ auf die Waage.

Das letzte Glöckchen E, FNr. 405-E, gleicht den zwei anderen. Knapp unterhalb des Scheitels befindet sich ein kleines rundes Loch. Ein kleiner fragmentierter, mittels Ring am Scheitelinneren befestigter Eisenklöppel hat sich erhalten (Abb. 3/5; 4/4a-b, jeweils das linke Exemplar). Das Glöckchen ist 1,6 cm hoch, hat einen Durchmesser von $1,8 \mathrm{~mm} \times 1,7 \mathrm{~mm}$ und eine Wandstärke von $1 \mathrm{~mm}$. Die Glocke wiegt $5 \mathrm{~g}$. 

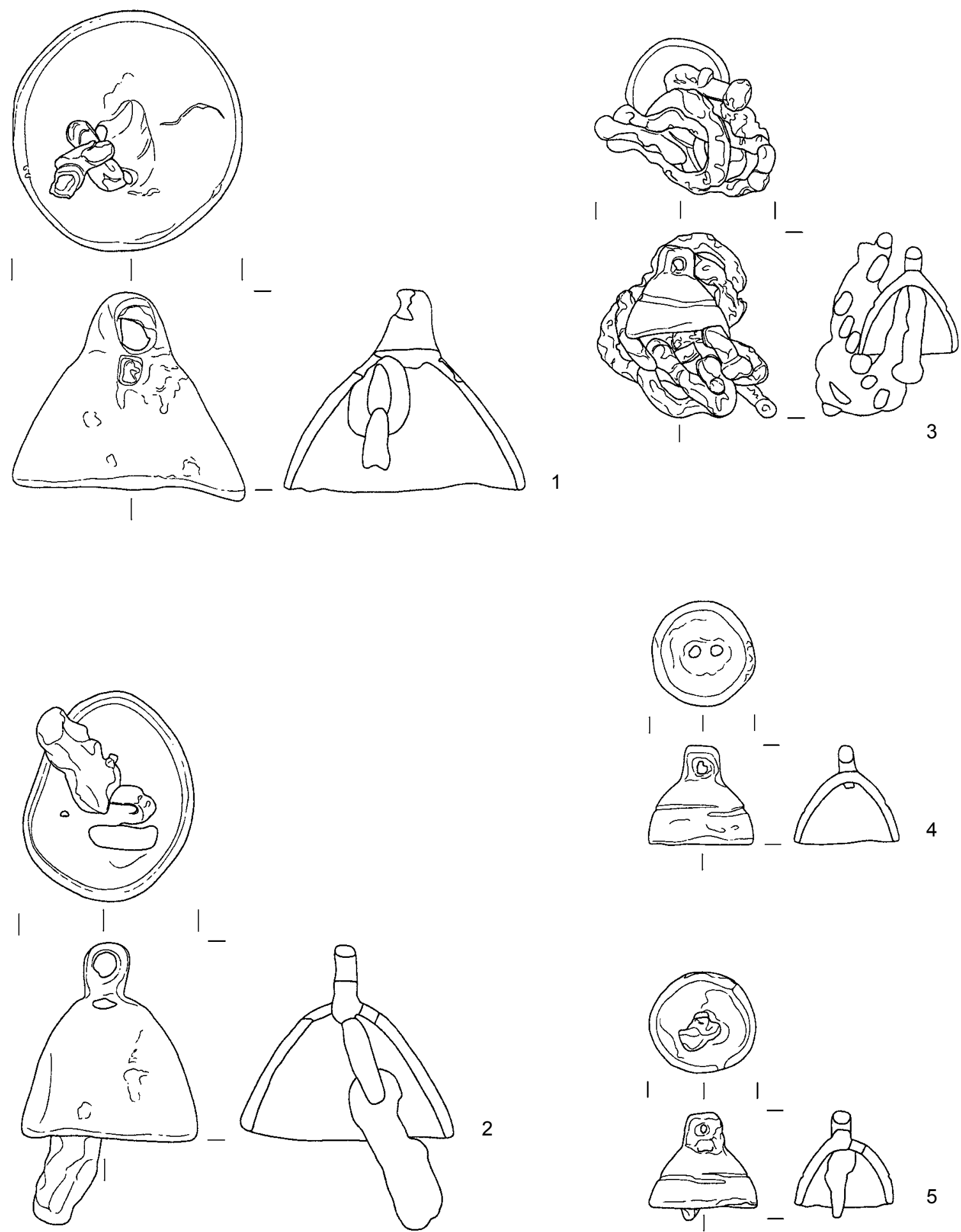
chen 405-D. - 5. Glöckchen 405-E (Zeichnung: J. M. Czubak, BDA). 

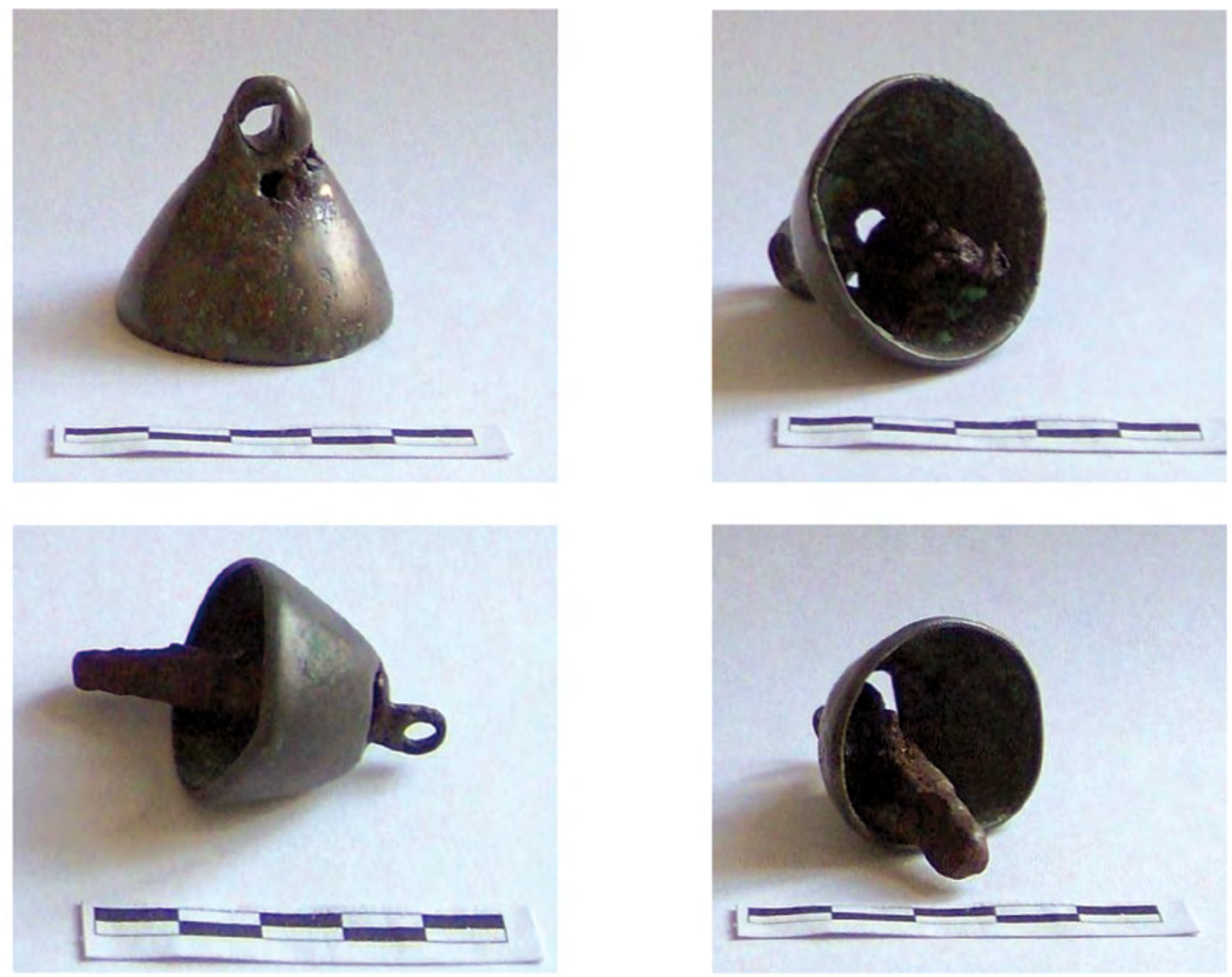

$1 a-b$
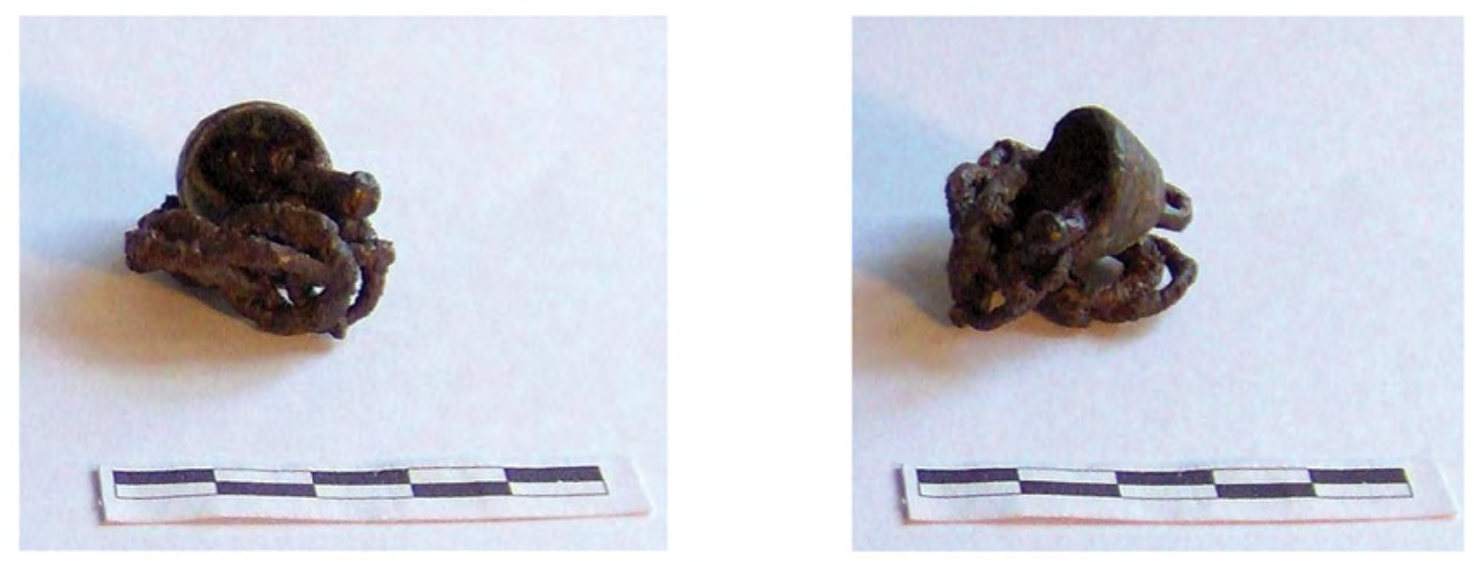

$2 a-b$
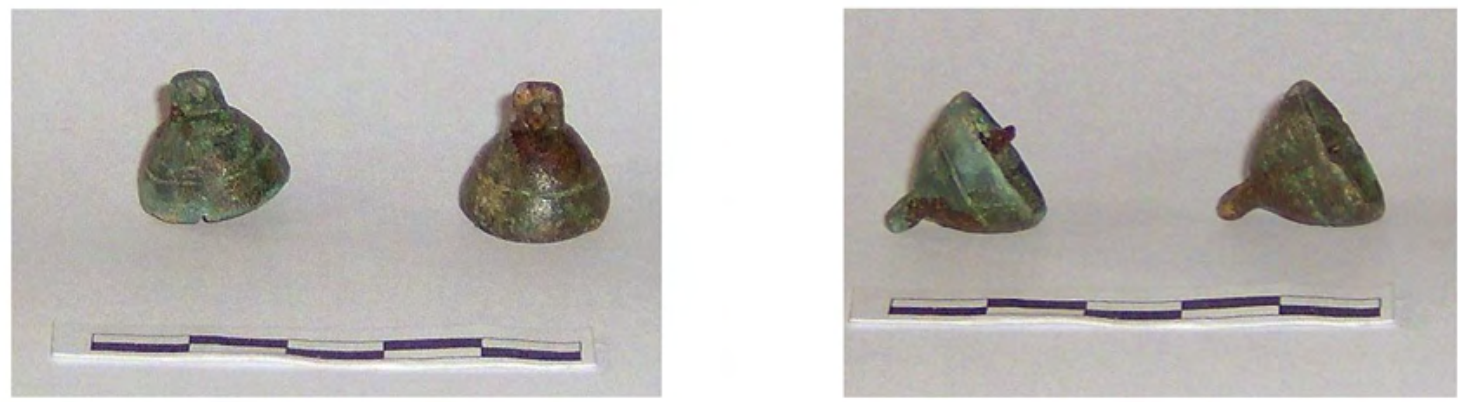

$3 a-b$

Abb. 4. Glocken aus Grab 157, Vösendorf-Laxenburger Straße. - 1/a-b. Glocke 405-A. - 2/a-b. Glocke 405-B. -3/a-b. Glöckchen 405-C. - 4/a-b. Glöckchen 405-D (rechts) und 405-E (links) (Fotos: B. M. Pomberger). 


\section{Anfertigung von Glocken und Klöppeln}

Fragmente awarischer Glockengussformen wurden bislang nicht entdeckt, da diese entweder beim Befreien der Glocke aus der tönernen Form vollkommen zerstört oder die Fragmente nicht als Gussform erkannt wurden. Man kennt jedoch einige Gussformen aus dem hellenistischen und römischen Ägypten. ${ }^{4}$ Der Guss von Glocken geschieht mittels Wachsausschmelzverfahren in einer mehrteiligen Form. Über einen dem Modell entsprechend geformten, gemagerten Lehmkern wird eine Wachsschicht in negativer Modellform - die falsche Glocke - gelegt. Dieses Gebilde wird wiederum mit einer Schicht Ton - dem Mantel - in zweischaliger Form umhüllt. Nach dem Trocknen wird das Gebilde erwärmt, um das Wachs über den Gusskanal ausrinnen zu lassen. Danach erfolgt der Guss. Die Glockenspeise - eine Kupferlegierung - wird erhitzt und in die Form gefüllt. Nach dem Erkalten wird die tönerne Form vorsichtig zerstört, um die Glocke zu befreien. Untersuchungen zur Zusammensetzung der Glockenspeise awarischer Glocken, die für deren Klang maßgeblich ist, fehlen bislang.

Die Klöppel der hier untersuchten awarischen Glöckchen aus dem Gräberfeld Vösendorf-Laxenburger Straße wurden aus geschmiedeten Eisenstäben hergestellt, die in ihrer Mitte um einen Eisenring gebogen und zusammengeschmiedet wurden. Hier sind zwei Formen zu unterscheiden (Abb. 5). Die Eisenstäbe der Klöppel größerer Glocken weisen eine dickere Klöppelmitte auf und verlaufen etwas schmäler zugerichtet in leicht abgerundeten Enden. Die Maße des gebogenen Stabes betragen ca. $5 \mathrm{~mm}$ in der Breite und $7 \mathrm{~mm}$ in der Höhe, wodurch der Klöppel eine Gesamtdicke von ca. $10 \mathrm{~mm}$ aufweist. Die Klöppelöse - der Ring - wird an die innere Scheitelwölbung der Glocke gelötet. Eine andere Variante der Befestigung der Öse besteht darin, zwei Löcher in Scheitelnähe zu bohren und darin den Ring einzuhängen.

Eine Besonderheit ist bei den Klöppeln der Miniaturglocken festzustellen. Der in der Mitte um einen Ring um ca. 330 Grad gebogene Eisenstab endet in zwei kugelförmig verdickten Enden. Die verdickten Klöppelenden dienen nicht dem Anschlagen - dies geschieht in der Klöppelmitte -, sondern verhindern ein Herausschlüpfen des Klöppels aus der Öse. Das gemessene Maß des geschmiedeten Klöppelstabes beträgt $4 \times 4 \mathrm{~mm}$ in der Dicke, jenes der Enden $5 \times$ $5 \mathrm{~mm}$. Auch hier ist die Gesamtlänge des Klöppels samt Öse doppelt so lang wie die Höhe des Glockenmantels. Überlange Klöppel dürften eine Eigenheit der Glocken aus dem euroasiatischen Steppengebiet bzw. der Steppennomaden

4 Hickmann 1956, 267-276.

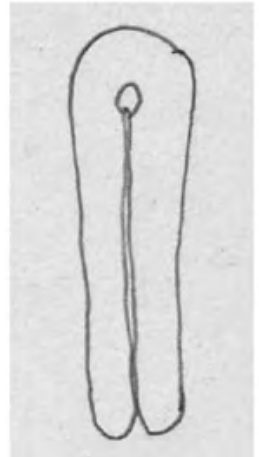

Klöppeltyp 1

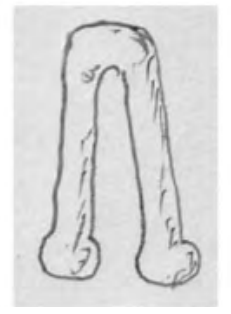

Klöppeltyp 2
Abb. 5. Skizzen der Klöppeltypen awarischer Glocken (Grafik: B. M. Pomberger).

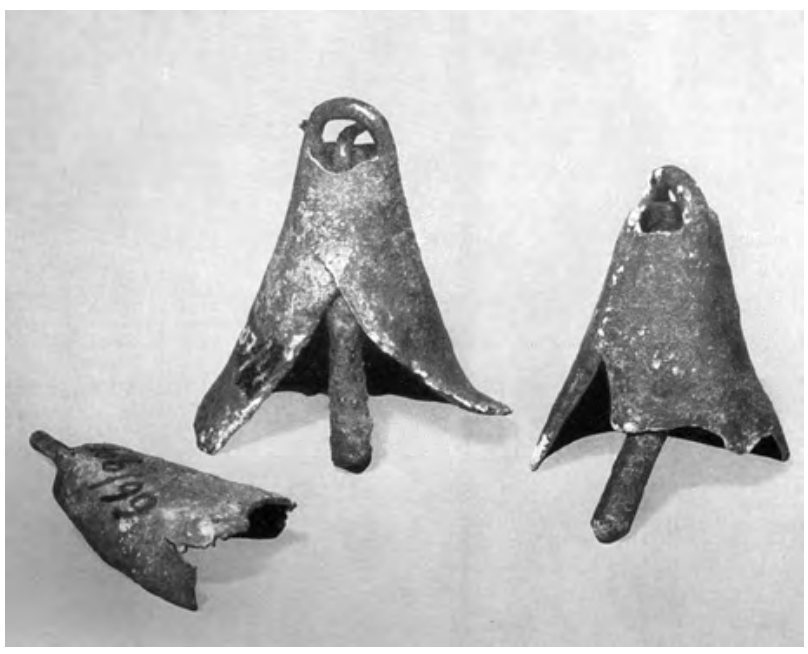

Abb. 6. Skythische Glocken aus Gyöngyös, Ungarn (BAKAy 1971, Taf. III).

sein, wie Abbildungen skythischer Glocken aus Ungarn zeigen (Abb. 6). ${ }^{5}$

\section{Instrumentalkundliche Einordnung nach der Systematik von Hornbostel und Sachs}

Glocken als Überbegriff für große und kleine Glocken (Glöckchen) sind nach der Systematik der Musikinstrumente von Hornbostel und Sachs Idiophone, das heißt „Selbstklinger“. Archäologen unterscheiden des Öfteren nicht genau zwischen Glocken und Schellen, welche auch den Idiophonen zuzuordnen sind. Der Unterschied zwischen Glocken und Schellen besteht darin, dass sich Glocken aus Klangschalen entwickelt haben, als unmittelbar geschlagene

5 BAKAY 1971, Taf. III. 
Idiophone angesprochen werden, in weiterer Folge Aufschlagidiophone sind, die mit einem Stab oder Hammer von außen angeschlagen werden. Schellen hingegen gehören der Gruppe der mittelbar geschlagenen Idiophone an. Sie sind als Schüttelidiophone und in weiterer Folge als metallene Gefäßrasseln zu klassifizieren. ${ }^{6}$

Die awarischen Glocken sind den Hängeglocken mit Klöppel (Systemnummer 111.242.122) zuzuordnen. Glocken zählen zu den Aufschlaggefäßen mit stummen Scheiteln. Sie schwingen auf drei verschiedene Arten: erstens wie eine Stimmgabel, zweitens wie eine schwingende Platte in Kreislinien und Meridianen, und zuletzt kommt noch die Schwerpunkt-Kreislinienschwingung dazu. ${ }^{8}$

\section{Akustische Untersuchungen der Glöckchen aus dem Grab 157, Vösendorf-Laxenburger Straße}

Für die akustischen Untersuchungen wurden alle Glöckchen aus Grab 157 mit einem Eisenstift angeschlagen, da ihre Klöppel korrodiert oder angerostet sind. Ihr Klang wurde mit einem Aufnahmegerät festgehalten. Diese Tonaufnahmen wurden in das Audiovisualisierungsprogramm Adobe Audition 3.0 eingespeist und Frequenzanalysen hergestellt. Die Schallpegel der Glocken wurden mit einem Schallpegelmessgerät im Abstand von $17 \mathrm{~cm}$ zum Mikrophon gemessen. Mit Hilfe des Tontechnik-Rechners sengpielaudio ${ }^{9}$ wurde die Reichweite der Idiophone bei einem Umgebungsschallpegel von $42 \mathrm{~dB}$ kalkuliert.

Der Grundton der Glocke 405-A liegt bei $2952 \mathrm{~Hz}$ (F\#7/F\#4). Ihr gemessener Schallpegel beträgt $51 \mathrm{~dB}$ und reicht ca. 0,48 m weit. Bei dieser Glocke konnten noch drei weitere markante Teiltöne eruiert werden (Abb. 7, Tab.1). Glocke 405-B klingt bei $2621 \mathrm{~Hz}$ (E7-7 Cent/E4-7 Cent) mit einem Schallpegel von $44 \mathrm{~dB}$ und reicht 0,21 m weit (Abb. 8, Tab.1). Der Klang der Glocke ist schlecht, da der Klöppel an der Glockenwand durch Korrosion anhaftet und somit das Schwingen des Resonanzkörpers behindert. Das Bild der Spektralfrequenzanalyse zeigt zwei starke Teiltöne an. Bei Glocke 405-C sind keine akustischen Untersuchungen möglich, da die Eisenkette am Glockenkörper ankorrodiert

6 Die Systematik der Musikinstrumente von Hornbostel und Sachs beruht in erster Linie auf der Art der Klangerzeugung (IdiophonMembranophon-Aerophon-Chordophon) und in zweiter Linie, mit Unterteilungen, auf der Konstruktion des Musikinstrumentes und seiner Charakteristik. Daraus leitet sich für jedes Instrument eine entsprechende Systemnummer ab.

7 Hornbostel, Sachs 1914. - MiMO H-S Klassifikation vom 8.7.2011: MIMO 2011.

8 ELLERHORST 1957, 41.

9 http://www.sengpielaudio.com/Rechner-entfernung.htm (letzter Zugriff 2.3.2017). ist. Das Glöckchen 405-D wiederum konnte bemessen werden. Es erklingt bei $11199 \mathrm{~Hz}$ (F9+3 Cent/F6+3 Cent) und weist nur einen Teilton bei $17020 \mathrm{~Hz}$ auf. Sein Schallpegel beträgt $37.5 \mathrm{~dB}$ und reicht $0,10 \mathrm{~m}$ weit (Abb. 9, Tab.1). Das letzte Glöckchen, Fundnummer 405-E, hat einen Grundton von $10249 \mathrm{~Hz}$ (E9-49 Cent/E6-49 Cent). Der einzige markante Teilton liegt bei $11630 \mathrm{~Hz}$. Die kleine Glocke mit einem Schallpegel von $37 \mathrm{~dB}$ reicht 0,10 m weit (Abb. 10, Tab.1).

Tab. 1. Grundtöne und Teiltöne der Glocken aus Grab 157, Vösendorf-Laxenburger Straße. Abkürzungen: FNr. = Fundnummer, $\mathrm{Hz}=$ Hertz.

\begin{tabular}{|l|c|c|c|c|}
\hline FNr. & Grundton & 1. Teilton & 2. Teilton & 3. Teilton \\
\hline 405-A & $2952 \mathrm{~Hz}=$ F\#7 & $6338 \mathrm{~Hz}$ & $11490 \mathrm{~Hz}$ & $17420 \mathrm{~Hz}$ \\
\hline $405-\mathrm{B}$ & $2621 \mathrm{~Hz}=\mathrm{E} 7-7$ & $5334 \mathrm{~Hz}$ & $8726 \mathrm{~Hz}$ & - \\
\hline $405-\mathrm{D}$ & $11199 \mathrm{~Hz}=\mathrm{F} 9+3$ & $17020 \mathrm{~Hz}$ & - & - \\
\hline $405-\mathrm{E}$ & $10249 \mathrm{~Hz}=\mathrm{E} 9-49$ & $11630 \mathrm{~Hz}$ & - & - \\
\hline
\end{tabular}

Das Zusammenklingen der Glocken ergibt folgendes Klangbild: A8-C\#9-E9-F9. Die Grundtöne der ersten und zweiten Glocke erklingen zusammen in einer großen Terz. Die dritte Glocke dazu geläutet ergibt einen Dur-Dreiklang. Das letzte Glöckchen stört diese Harmonie mit einem Tonschritt einer kleinen Sekund. $\mathrm{Ob}$ das harmonische Zusammenklingen der beiden größeren Glocken bewusst getroffen wurde oder aber ein Zufall ist, kann nicht gesagt werden. Die kleinen Glöckchen jedoch, die alle fast gleich groß sind, aber doch verschiedene Grundtöne in wahrscheinlich kleinen Tonschritten haben, ergeben im Zusammenklang Dissonanzen. Keines der Glöckchen besitzt eine Reichweite von mehr als 0,5 m. ${ }^{10}$

\section{Typologie awarischer Glocken}

Basierend auf Peter Stadlers Glockentypologie ${ }^{11}$ und anhand aller 72 bekannten Glockenfunde aus 53 awarenzeitlichen Gräbern Österreichs, der Slowakei, Ungarns und Serbiens (davon 43 Bronzeglocken und 19 Eisenglocken) sowie aus 10 Streufunden (bestehend aus neun Bronzeglocken und einer Eisenglocke) (Abb. 11, Tab. 2) wurde eine neue Typologie erstellt.

Bronzeglocken wurden gegossen, Eisenglocken geschmiedet. Gegossene Glocken sind in ganz Asien und

10 Die erste Autorin hat ein Video mit den Tonaufnahmen aller Glöckchen aus Grab 157 erstellt und es im Internet zur Verfügung gestellt: Avaric Sounds II, https://www.youtube.com/ watch?v=YXSCYgoVXhA (letzter Zugriff 26.8.2018). 11 Stadler 2005, CD-Rom. 


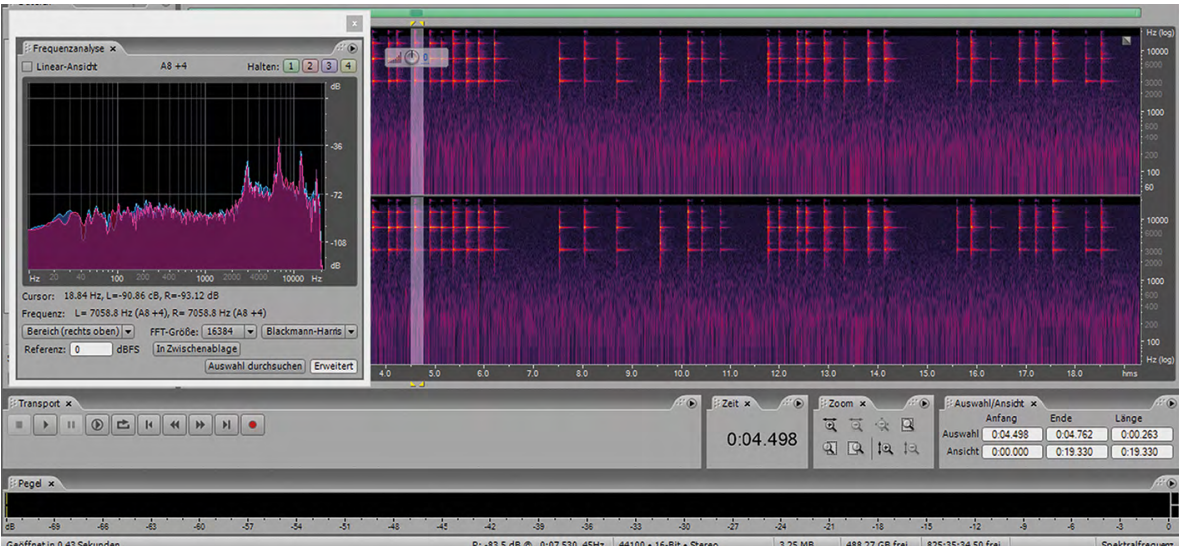

\begin{tabular}{|c|c|c|}
\hline \multicolumn{3}{|c|}{ Berechnung der Entfernung $\boldsymbol{r}_{\mathbf{2}}$, bei dem der Schallpegel $\boldsymbol{L}_{\mathbf{2}}$ zu finden ist. } \\
\hline $\begin{array}{l}\text { Schallpegel } L_{1} \\
\text { bei Bezugs-Entfernung } \boldsymbol{r}_{\mathbf{1}}\end{array}$ & $\begin{array}{l}\text { Bezugs-Entfernung } \boldsymbol{r}_{\mathbf{1}} \\
\text { von der Schallquelle }\end{array}$ & \multirow[t]{2}{*}{ Suche nach $\boldsymbol{r}_{\mathbf{2}}$} \\
\hline dBSPL & 0.17 & \\
\hline \multirow{2}{*}{\begin{tabular}{|l} 
Schallpegel $L_{2}$ \\
bei anderer Entfernung $\boldsymbol{r}_{\mathbf{2}}$ \\
\begin{tabular}{|lc}
42 & dBSPL \\
\end{tabular} \\
\end{tabular}} & $\begin{array}{l}\text { Andere Entfernung } r_{\mathbf{2}} \\
\text { von der Schallquelle }\end{array}$ & $\begin{array}{l}\text { Entfernungsänderung } \\
\Delta r=r_{2}-r_{1}\end{array}$ \\
\hline & 0.48 & 0.31 \\
\hline & Berechnen & Rücksetzen \\
\hline
\end{tabular}

Abb. 7. Messungen der Glocken aus Grab 157, Vösendorf-Laxenburger Straße. Frequenzanalyse und Reichweitenkalkulation Glocke 405-A (Erstellung: B. M. Pomberger).

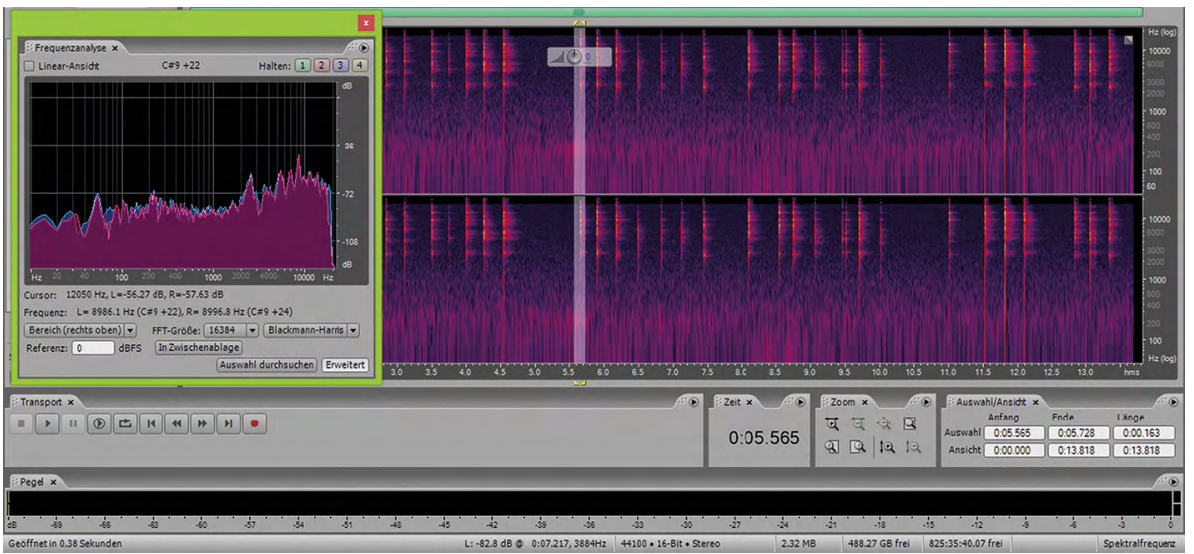

\begin{tabular}{|c|c|c|}
\hline \multicolumn{3}{|c|}{ Berechnung der Entfernung $\boldsymbol{r}_{\mathbf{2}}$, bei dem der Schallpegel $\boldsymbol{L}_{\mathbf{2}}$ zu finden ist. } \\
\hline $\begin{array}{l}\text { Schallpegel } L_{1} \\
\text { bei Bezugs-Entfernung } \boldsymbol{r}_{\mathbf{1}}\end{array}$ & $\begin{array}{l}\text { Bezugs-Entfernung } \boldsymbol{r}_{\mathbf{1}} \\
\text { von der Schallquelle }\end{array}$ & \multirow[t]{2}{*}{ Suche nach $r_{2}$} \\
\hline dBSPL & 0.17 & \\
\hline \multirow{3}{*}{\begin{tabular}{|l} 
Schallpegel $L_{2}$ \\
bei anderer Entfernung $r_{2}$ \\
$42 \quad$ dBSPL \\
\end{tabular}} & $\begin{array}{l}\text { Andere Entfernung } \boldsymbol{r}_{\mathbf{2}} \\
\text { von der Schallquelle }\end{array}$ & $\begin{array}{l}\text { Entfernungsänderung } \\
\Delta r=r_{2}-r_{1}\end{array}$ \\
\hline & 0.21 & 0.04 \\
\hline & Berechnen & Rücksetzen \\
\hline
\end{tabular}

Abb. 8. Messungen der Glocken aus Grab 157, Vösendorf-Laxenburger Straße. Frequenzanalyse und Reichweitenkalkulation Glocke 405-B

(Erstellung: B. M. Pomberger). 


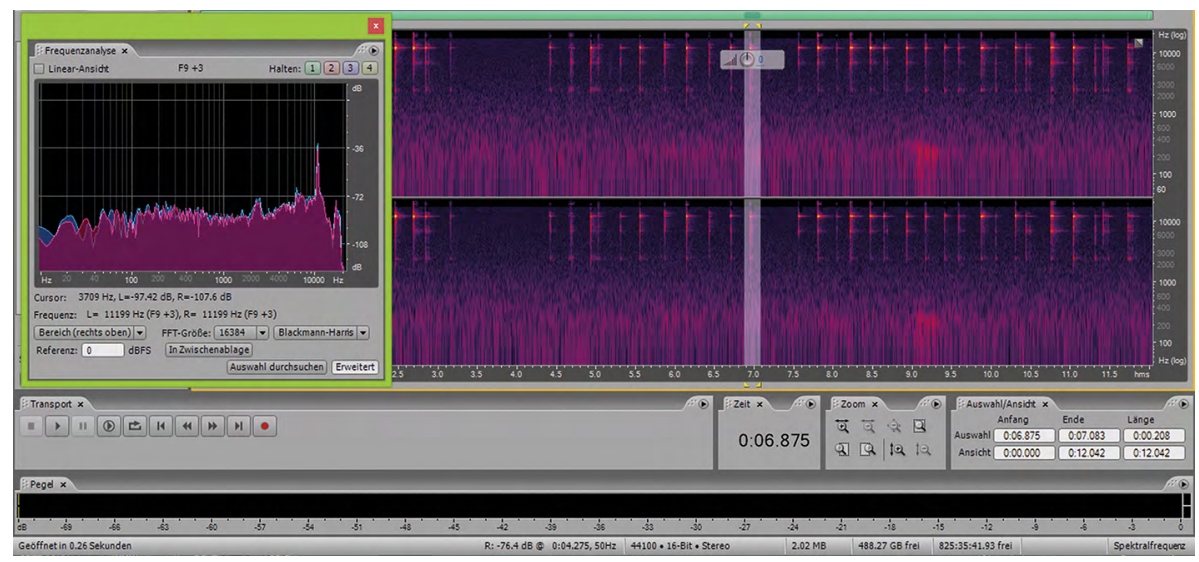

\begin{tabular}{|c|c|c|}
\hline \multicolumn{3}{|c|}{ Berechnung der Entfernung $\boldsymbol{r}_{\mathbf{2}}$, bei dem der Schallpegel $\boldsymbol{L}_{\mathbf{2}} \mathrm{zu}$ finden ist. } \\
\hline $\begin{array}{l}\text { Schallpegel } L_{1} \\
\text { bei Bezugs-Entfernung } r_{1}\end{array}$ & $\begin{array}{l}\text { Bezugs-Entfernung } r_{1} \\
\text { von der Schallquelle }\end{array}$ & \multirow[t]{2}{*}{ Suche nach $\boldsymbol{r}_{2}$} \\
\hline dBSPL & 0.17 & \\
\hline \multirow{2}{*}{ 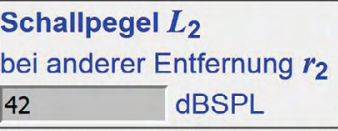 } & $\begin{array}{l}\text { Andere Entfernung } \boldsymbol{r}_{\mathbf{2}} \\
\text { von der Schallquelle }\end{array}$ & $\begin{array}{l}\text { Entfernungsänderung } \\
\Delta r=r_{2}-r_{1}\end{array}$ \\
\hline & 0.1 & -0.07 \\
\hline & Berechnen & Rücksetzen \\
\hline
\end{tabular}

Abb. 9. Messungen der Glocken aus Grab 157, Vösendorf-Laxenburger Straße. Frequenzanalyse und Reichweitenkalkulation Glocke 405-D (Erstellung: B. M. Pomberger).

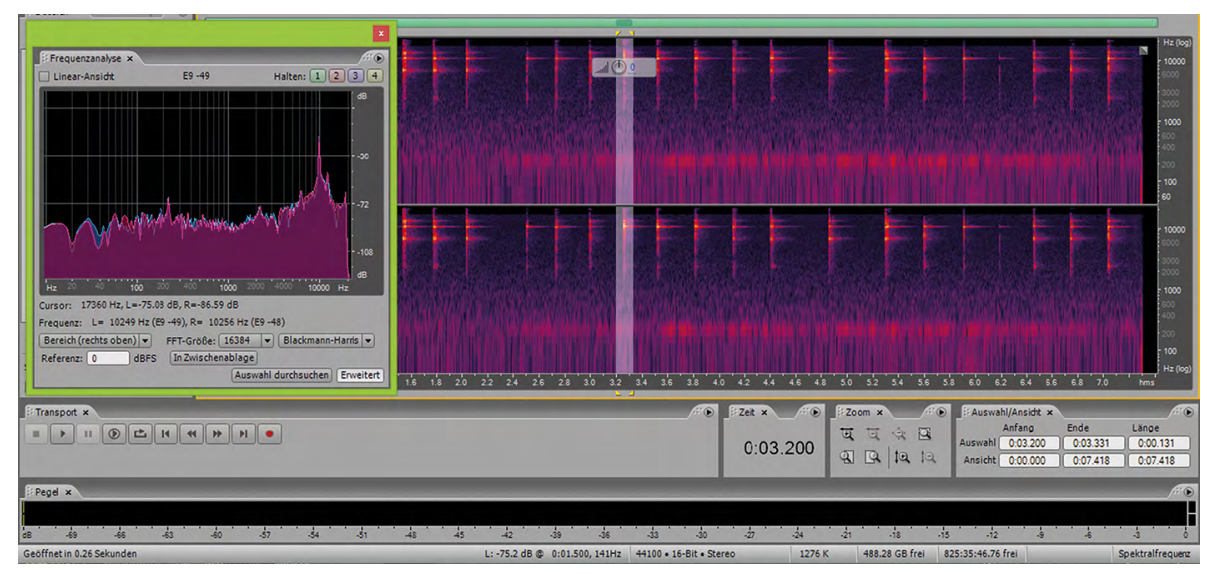

\begin{tabular}{|c|c|c|}
\hline \multicolumn{3}{|c|}{ Berechnung der Entfernung $\boldsymbol{r}_{\mathbf{2}}$, bei dem der Schallpegel $\boldsymbol{L}_{\mathbf{2}} \mathrm{zu}$ finden ist. } \\
\hline $\begin{array}{l}\text { Schallpegel } L_{1} \\
\text { bei Bezugs-Entfernung } r_{1}\end{array}$ & $\begin{array}{l}\text { Bezugs-Entfernung } r_{1} \\
\text { von der Schallquelle }\end{array}$ & \multirow[t]{2}{*}{ Suche nach $r_{2}$} \\
\hline dBSPL & 0.17 & \\
\hline \multirow{2}{*}{ 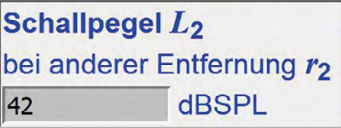 } & $\begin{array}{l}\text { Andere Entfernung } r_{2} \\
\text { von der Schallquelle }\end{array}$ & $\begin{array}{l}\text { Entfernungsänderung } \\
\Delta r=r_{2}-r_{1}\end{array}$ \\
\hline & 0.1 & -0.07 \\
\hline & Berechnen & \\
\hline
\end{tabular}

Abb. 10. Messungen der Glocken aus Grab 157, Vösendorf-Laxenburger Straße. Frequenzanalyse und Reichweitenkalkulation Glocke 405-E (Erstellung: B. M. Pomberger). 
Tab. 2. Übersicht awarenzeitlicher Glockenfunde. Abkürzungen: FA = Frühawarisch, MA = Mittelawarisch, SPA = Spätawarisch.

\begin{tabular}{|l|l|c|c|c|c|c|c|c|c|}
\hline Land & Datierung & $\begin{array}{c}\text { Fundorte } \\
\text { Gesamt }\end{array}$ & $\begin{array}{c}\text { Fundorte mit } \\
\text { Gräbern }\end{array}$ & $\begin{array}{c}\text { Kontexte } \\
\text { Gesamt }\end{array}$ & Gräber & $\begin{array}{c}\text { Streu- } \\
\text { funde }\end{array}$ & $\begin{array}{c}\text { Glocken } \\
\text { Gesamt }\end{array}$ & $\begin{array}{c}\text { Bronze- } \\
\text { glocken }\end{array}$ & $\begin{array}{c}\text { Eisen- } \\
\text { glocken }\end{array}$ \\
\hline Österreich & MA-SPA, 7.-9. Jh. & 8 & 7 & 10 & 9 & 1 & 14 & 10 & 4 \\
\hline Slowakei & MA, 2. Hälfte 7. Jh. & 1 & 1 & 1 & 1 & 0 & 1 & 1 & 0 \\
\hline Ungarn & FA-SPA, 6.-9.Jh. & 27 & 22 & 46 & 40 & 6 & 51 & 35 & 16 \\
\hline Serbien & FA-SPA, 6.-7./8. Jh. & 4 & 3 & 6 & 3 & 3 & 6 & 6 & 0 \\
\hline
\end{tabular}

Europa zu finden, Eisenglocken hingegen dürften europäischen Ursprunges sein. Die awarischen Glocken sind kleine Handglocken und Glöckchen. ${ }^{12}$

\subsection{Bronzeglocken}

Die Basen awarischer Bronzeglocken sind kreisrund oder rechteckig-quadratisch (Abb. 12). Der Klöppel ist an einer am inneren Glockenscheitel angelöteten Öse befestigt oder an einem kleinen, an der Glockenwand angelöteten Querstab eingehängt. Einige Glocken weisen am Scheitelbereich zwei gegenständige Löcher auf, durch die ein Ring geführt wurde, in dem der Klöppel eingehängt werden konnte.

\section{Bronzeglocken mit kreisrunder Basis}

Typ 1 besitzt eine kreisrunde Basis sowie einen kalottenförmigen Glockenkörper. Variante A weist keine Verzierung am Mantel auf, die Variante B ist mit einer mittig umlaufenden Rille verziert und tritt als größere und kleinere Form auf, Variante $\mathrm{C}$ hat einen deutlich abgesetzten, die Glockenöffnung umlaufenden Wulst, und Variante D ist mit Kreisaugen verziert. Die kalottenförmigen Glocken dürften sich von römischen Glocken, und zwar von Typ 5 nach der Typologie von Pomberger, ableiten. ${ }^{13}$ Kalottenförmige Glocken treten bereits im antiken Griechenland auf. ${ }^{14}$ Attila Kiss verweist bei dem Glockenfund aus Grab 12, KölkedFeketekapu A, auf spätantike Wurzeln. ${ }^{15}$

Typ 2 hat einen getreppt geformten Glockenkörper mit rundem Scheitel und leitet sich vom römischen Glockentyp 3/Variante B nach der Typologie von Pomberger ab. Kegelförmig mit umlaufender Rille stellt sich Typ 3 dar. Er dürfte eine Weiterentwicklung einer sarmatischen Glockenform mit ihrer runden Öse sein (Abb. 13), erinnert aber

12 Der Begriff „Glocke“ steht in diesem Artikel für alle awarischen Glockenfunde. Große Glocken wie Kirchenglocken wurden erst ab dem Mittelalter erzeugt.

13 Pomberger 2018, 9-11, Abb. 10.

14 Villing 2002, Abb. 20-22.

15 Kiss 1996, 268. auch an antike griechische Glocken aus Samos. ${ }^{16}$ Letztendlich steht noch ein Objekt als Typ 4 zur Diskussion: Es handelt sich um ein zylindrisches Stück mit rundem Scheitel, umlaufendem Wulst und etwas ausladender Öffnung. Ob es sich dabei um eine Glocke oder einen Anhänger handelt, kann nur eine genaue Untersuchung des Objektes bringen, da der Autor keine Hinweise auf einen Klöppel bringt. ${ }^{17}$ Das Objekt erinnert an antike griechische Glocken aus Tanagra $^{18}$ und Pherai. ${ }^{19}$

\section{Bronzeglocken mit rechteckig-quadratischer Basis}

Typ 5 mit ebenfalls pyramidenförmigem Körper, annähernd geradem Scheitel und Füßchen an der Basis erinnert an den römischen Glockentyp 1/Variante F. ${ }^{20}$ Als Typ 6 wird eine Glocke mit pyramidenförmigem Mantel, geradem Scheitel und runder Öse vorgeschlagen. Er dürfte eine Ähnlichkeit mit dem römischen Typ 1/Variante E haben. ${ }^{21}$ Einer Zipfelmütze mit runder Öse gleicht Typ 7, vermutlich eine Weiterführung eines östlichen Glockentyps.

Typ 1/Variante A kommt während der ganzen Zeit des Khaganats vor, von Frühawarisch bis Spätawarisch. Er ist 20-mal in 19 Gräbern belegt. Typ 1/Variante B groß erscheint nur einmal in der mittelawarischen Periode als Unikat in einem Grabkontext. Variante B klein tritt in frühawarischen und spätawarischen Gräbern auf. Sie ist insgesamt neunmal in sechs Gräbern nachgewiesen. Typ 1/Variante C ist nur einmal in einem frühawarischen $G$ rab nachgewiesen. Typ 1/Variante D kennen wir je einmal aus frühawarischer, aus mittelawarischer-spätawarischer und aus spätawarischer Zeit. Typ 2 ist durch einen Fund aus der Frühawarenzeit belegt. Typ 3 ist einmal aus spätawarischer Zeit bekannt, tritt jedoch im Grab 118, Suuk-Su, Jalta, Ukraine,

16 Villing 2002, 262-263, Abb. 30-33.

17 Kiss 1996, Taf. 32/A 91/3.

18 Villing 2002, 264, Abb. 34.

19 VILling 2002, 261, Abb. 28-29.

20 Pomberger 2018, 9-10, Abb. 9.

21 Pomberger 2018, 9-10, Abb. 9. 
das ins letzte Drittel des 6. Jhs. datiert, gemeinsam mit dem Typ 1/Variante B klein auf. ${ }^{22}$ Ebenso taucht er wieder in magyarischer Zeit im Gräberfeld von Györ auf. ${ }^{23}$ Typ 4 ist nur durch ein Stück in der frühawarischen Periode belegt. In den Stufen Frühawarisch bis Mittelawarisch I ist Typ 5 durch zwei Objekte bekannt. Typ 6, vertreten durch ebenfalls zwei Stücke, ist ein Durchläufer von Frühawarisch bis Spätawarisch, und Typ 7 - nur ein Stück ist belegt - dürfte Mittel- bis Spätawarisch datieren (Tab. 3). An Streufunden gibt es fünf Glocken des Typs 1/Variante A, ein Stück wahrscheinlich des Typs 1/Variante B klein und zwei Stücke von Typ 1/Variante C. Ein Streufund gehört Typ 5 an.

\subsection{Eisenglocken}

Eisenglocken weisen eine rechteckige, ovale oder kreisrunde Basis auf (Abb. 12).

\section{Eisenglocken mit rechteckiger Basis}

Diese Glockenform, Typ 1, hat einen trapezförmigen Glockenmantel mit geradem Scheitel und einen Bandhenkel. Als Variante A wird die gedrungene breite Form, als Variante $\mathrm{B}$ die Hochform bezeichnet. Es handelt sich um eine Weiterführung des römischen Typs $1 .^{24}$ Typ 2 besitzt einen runden Scheitel. Es handelt sich um eine Weiterführung des römischen Bronzeglockentyps 1/Variante A. ${ }^{25}$

\section{Eisenglocken mit ovaler Basis}

Typ 3 ist ein hoher Stumpfkegel mit flachem Scheitel und Bandhenkel.

\section{Eisenglocken mit kreisrunder Basis}

Als Typ 4 werden Glocken mit kalottenförmigen Körpern bezeichnet.

Typ 1/Variante A ist in zwei Gräbern der Mittel- und/ bis Spätwarenzeit zu finden (je ein Stück). Variante B, belegt durch drei Funde, erscheint im Früh-, Mittel- und Spätawarischen. Der Typ 2 ist in allen drei Zeitabschnitten durch insgesamt sechs Objekte in fünf Gräbern belegt. Typ 3 datiert mit vier Funden aus drei Gräbern in die frühawarische und mittel- bis spätawarische Zeit und Typ 4, zweimal in Gräbern nachgewiesen, in die mittelawarisch-spätawarische Periode. Zusätzlich gibt es noch eine Eisenglocke des Typs 3 als Streufund (Tab. 3).

22 UenZe 1966, 144-145, Abb. 2/7-8.

23 BÖRZSÖNYI 1906, 319.

24 Pomberger 2018, 13, Abb. 14.

25 Pomberger 2018, 10, Abb. 9.

\subsection{Zeitstellung der Glocken}

Vergleicht man das Vorkommen der Glocken anhand ihrer datierten Befunde, so entsteht folgendes Bild: In frühawarischer Zeit sind Glocken durch 25 Stück (21 Fundkontexte) am häufigsten vertreten. Im Zeitschabschnitt Frühawarisch bis Mittelawarisch werden zwei Objekte gestellt, gefolgt von neun Glocken aus mittelawarischer Zeit. In der Übergangszeit Mittelawarisch-Spätawarisch kommen sieben Stück vor, in spätawarischer Periode 15 Glocken (elf Kontexte). Vierzehn Funde aus dreizehn Fundkontexten, darunter acht Streufunde und fünf Gräber, konnten zeitlich nicht genau eingeordnet werden (Tab. 3).

\section{Gräber mit Glockenfunden aus dem awarischen Reich}

Gemessen an den tausenden awarischen Bestattungen stammen aus Gräbern relativ wenige Glockenfunde. Insgesamt sind es nur 62 Glocken aus 53 Gräbern. Dabei handelt es sich um neun Gräber aus Österreich (13 Glocken), 40 aus Ungarn (45 Glocken), drei Gräber aus Serbien mit je einer Glocke sowie ein Grab mit einer Glocke aus der Slowakei. Keine Funde liegen aus Rumänien vor, was wohl auf den Forschungsstand in diesem Land zurückzuführen ist. Bei der Untersuchung der Glocken lag das Augenmerk vor allem auf der Position im Grab. Die Toten gehören in 15 Gräbern (drei österreichische, zwölf ungarische) den Stufen Infans I-II an. Die Grabausstattung weist auf weibliche und männliche Kinder hin. Dazu kommen zwei Gräber aus Ungarn mit Personen juvenilen Alters sowie acht Erwachsene plus elf mögliche Erwachsene. Aus den restlichen 17 Gräbern liegen keine genauen Altersbestimmungen vor. Sieben Personen männlichen Geschlechts (nur Ungarn und Serbien) und 26 Personen weiblichen Geschlechts (alle vier Länder) sind in den „Glockengräbern“ sicher nachgewiesen. Dazu kommen zwei mögliche männliche und zwei mögliche weibliche Bestattungen. In den Beschreibungen der übrigen Befunde werden keine Angaben zum Geschlecht der Bestatteten erwähnt. Lediglich ein Pferd war mit einer Glocke ausgestattet (Tab. 3).

\subsection{Kinderbestattungen mit Glocken}

Aus Österreich gibt es neben dem Kindergrab aus Vösendorf-Laxenburger Straße jenes von der Goldenen Stiege, Mödling, Niederösterreich. Es handelt sich um Grab 354, in welchem das Kleinkind eine Eisenglocke im Bereich der linken Hand aufwies. ${ }^{26}$ Als dritte „österreichische“ Kinderbestattung mit Glocke ist das Grab 23b aus dem Gräberfeld Zwölfaxing zu nennen. Es handelt sich um ein Kind der

26 STAdler 2018 (Mödling-Goldene Stiege in Bilddatenbank Montelius nach F. Daim), 192, Taf. 263A. 


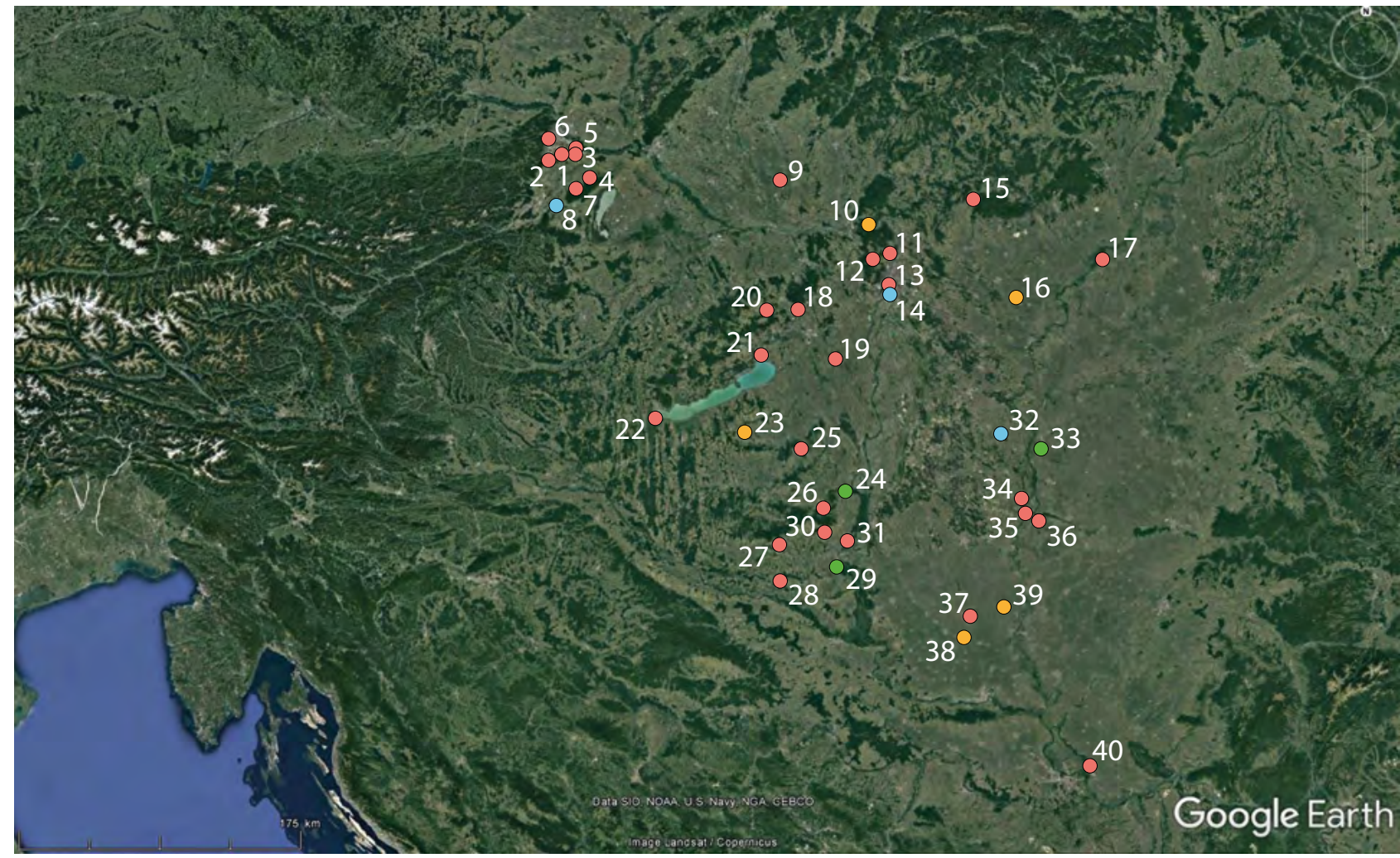

1 Grab bzw. 1 Streufund mit Glocke(n)/Fundort

2 Gräber bzw. 1 Grab und 1 Streufund mit Glocke(n)/Fundort
3 Gräber mit Glocke(n)/Fundort

5 Gräber mit Glocke(n)/Fundort

Abb. 11. Verbreitung der Glocken im awarischen Khaganat. - 1. Vösendorf-Laxenburger Straße. - 2. Mödling-An der Goldenen Stiege. 3. Zwölfaxing. - 4. Sommerein. - 5. Wien-Csokorgasse. -6. Wien, XIII. Bezirk. - 7. Leithaprodersdorf. - 8. Zillingtal. - 9. Nové Zámky. - 10. Pilismarót-Basaharc. - 11. Budakalász. - 12. Solymár. - 13. Budapest, XI. Bezirk, Fehérvári út 149-155. - 14. Budapest, XXI. Bezirk, Csepel-Háros Duna-gát. - 15. Pásztó. - 16. Alattyán Tulát. - 17. Tiszafüred. - 18. Csákberény-Orondpuszta. - 19. Sárosd. - 20. Bakonycsernye. -21. Balatonfúzfő. - 22. Keszthely Fenékpuszta. - 23. Andocs. - 24. Szekszárd-Bogyiszlói út. - 25. Regöly. - 26. Cikó. -27. PécsKöztemetô. - 28. Terehegy-Márfai dögkút. - 29. Kölked Feketekapu A. - 30. Szebény I. - 31. Dunaszekcsô. - 32. Gátér. - 33. SzegvárOromdúlö. - 34. Szeged-Fehértó „A“. - 35. Szeged. - 36. Deszk. - 37. Lovćenac (Sekić/Szeghegy). - 38. Vrbas. - 39. Bačko Petrovo Selo Čik. - 40. Pančevo.

(Konzept: P. Stadler; Hintergrund: Google Earth).

Abb. 12. Typentafel der Glocken (siehe S. 239).

Bronzeglocken. - Typ 1/Var. A: Grab 26, Budapest, XI. Bezirk, Fehérvári út 149 bis 155 (NAGY 1998, Taf. 79/26/3). - Typ 1/Var. B groß: Grab 83, Alattyán Tulát (Kovrig 1963, Taf. VII/45). - Typ 1/Var. B klein: Grab 157, Glocke E, Vösendorf-Laxenburger Straße (Zeichnung: J. M. Czubak, BDA). - Typ 1/Var. C: Grab 1, Lovćenac (Sekić/Szeghegy) (Hampel 1905, Bd. III, Taf. 497/d/1). - Typ 1/Var. D: Grab 12, Kölked Feketekapu A (Kiss 1996, Taf. 20/A12/1). - Typ 2: Grab 1, Budapest, XXI. Bezirk, Csepel-Háros Duna-gát (NAGY 1998, Taf. 99/B/5). - Typ 3: Grab 241, Tiszafüred (Garam 1995, Taf. 77/8). - Typ 4: Grab 91, Kölked Feketekapu A (Kiss 1996, Taf. 32/A 91/3). - Typ 5: Grab D-56, Zillingtal (STADLER 2018, Bilddatenbank Montelius nach F. Daim, Taf. 167/15). - Typ 6: Grab 119-2, Csákberény-Orondpuszta (Laszlo 2015, Taf. 10/119/2/6). - Typ 7: Grab 728, Szekszárd-Bogyiszlói út (Rosner 1999, Taf. 48/2) (Maßstab 1:2).

Eisenglocken. - Typ 1/Var. A: Grab 354, Mödling-Goldene Stiege (STAdler 2018, Bilddatenbank Montelius nach F. Daim, Taf. 263A/3) .Typ 1/Var. B: Grab 4, Terehegy-Márfai dögkút (Kiss 1977, Taf. LIX/3). - Typ 2: Grab 108, Szekszárd-Bogyiszlói út (Rosner 1999, Taf. 8/6). Typ 3: Grab 471, Kölked-Feketekapu A (Kiss 1996, Taf. 84/4). - Typ 4: Grab 227, Sommerein (Daim, Lippert 1984, Taf. 116/3) (Maßstab 1:2; Eisenglocke Typ 3 Maßstab 1:3).

(Konzept und Grafik: B. M. Pomberger). 


\section{Bronzeglocken}

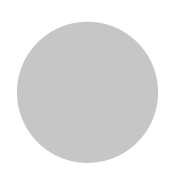

runde Basis

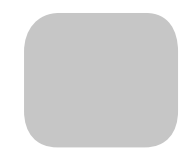

quadratische Basis

\section{Eisenglocken}

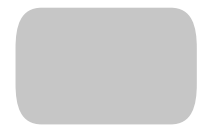

rechteckige Basis

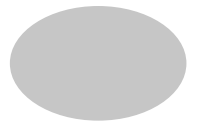

ovale Basis

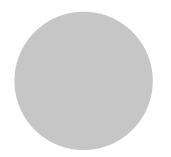

runde Basis

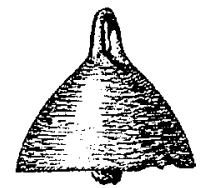

Typ 1

Variante A

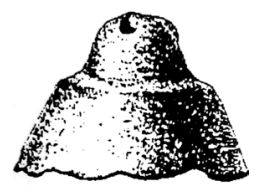

Typ 2

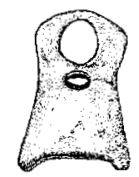

Typ 5

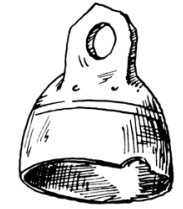

Typ 1

Variante B groß

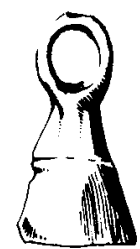

Typ 3

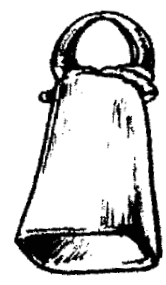

Typ 6

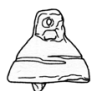

Typ 1

Variante B klein

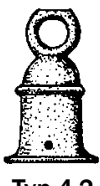

Typ 4 ?

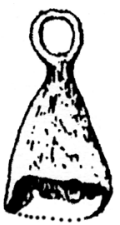

Typ 7

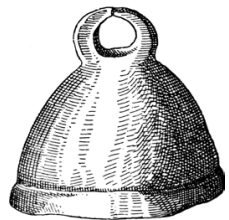

Typ 1

Variante $\mathrm{C}$

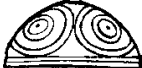

Typ 1

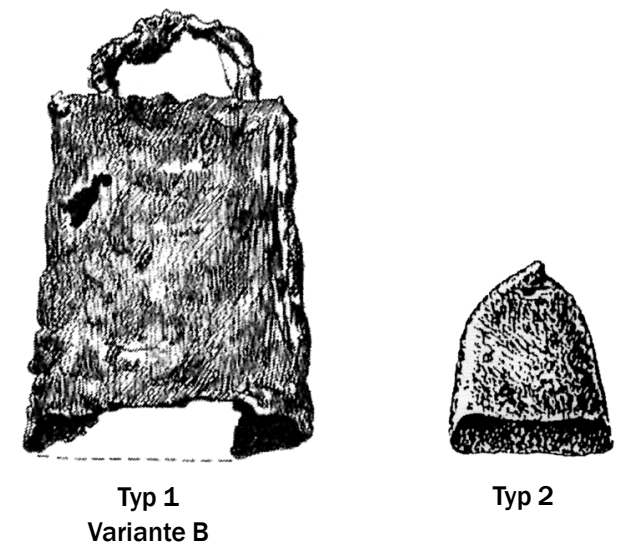

Abb. 12 (Bildunterschrift siehe S. 238). 


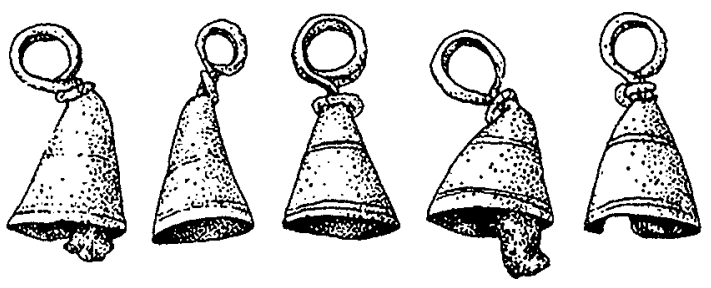

Abb. 13. Sarmatische Glocken aus Šarovce-Makócza domb, Grab 5/1955 1-6 (1:1) (Istvanovits, KulCár 1993, Taf. 9/10).

Stufe Infans I, bei dem das bronzene Idiophon im linken Beckenbereich lag. ${ }^{27}$ Eine weitere Eisenglocke befand sich in Grab 4 - ein Kleinkind (Stufe Infans I) - des Gräberfeldes Terehegy-Márfai dögkút. Hier lag das Objekt beim rechten Oberschenkel. ${ }^{28}$ Grab 381 des Gräberfeldes aus SzekszárdBogyiszlói út enthielt eine Kinderbestattung, bei der das Skelett vergangen war, jedoch eine Glocke aus Eisenblech im vermuteten Beckenbereich entdeckt wurde. ${ }^{29}$ Das völlig gestörte Grab 728 zählt ebenfalls als Kindergrab. Hier wurde eine aus Bronze gegossene Glocke mit ringförmiger Öse ausgegraben. ${ }^{30}$ Dem Kind aus Grab 108 des Gräberfeldes Szekszárd-Bogyiszlói út wurde eine Bronzeglocke, wohl an einer Kette aus Bronzedraht hängend, mitgegeben. Das Objekt lag auf dem linken Oberschenkel. ${ }^{31}$ In Grab 191, Szekszárd-Bogyiszlói út, wurde dem Knaben eine Eisenglocke in die linke Seite der Grabgrube mitgegeben. ${ }^{32}$ Aus AllatyánTulát ist das Grab 83 zu nennen, in dem ein 8-10-jähriges Kind (Infans II) begraben war. Die Bronzeglocke kam hier an der Außenseite des rechten Oberschenkels zu liegen. Über dem rechten Handknochen befand sich ein Knochenpfeiferl. ${ }^{33}$ Ein Mädchen der Altersstufe Infans II aus dem Grab 139, Kölked-Feketekapu A, hatte eine Glocke im Beinbereich. ${ }^{34}$ Ein weiteres Mädchen aus Kölked-Feketekapu A, Grab 144, trug die Glocke wohl um den Hals, da diese unter der rechten Seite des Schädels aufgefunden wurde. ${ }^{35}$ Aus Solymár liegt mit Grab 32 eine Kleinkindbestattung mit einer Eisenglocke zwischen Becken und Oberschenkeln vor. ${ }^{36}$ Es gibt keine genauen Angaben der Lage der Glocken aus den

27 Lippert 1969, 49, 129, Taf. 10/1; 78/1; 98/1.

28 Kiss 1977, 10, Abb. 67/2, Taf. LIX, XCII/9.

29 RosNer 1999, 53, Taf. 27.

30 Rosner 1999, 90, Taf. 48.

31 Rosner 1999, 22-23, 24, Abb. 5, Taf. 8/108/6.

32 Rosner 1999, 32, 130, Taf. 14/4; 53.

33 Kovrig 1963, 16, 148, Taf. VII/45-46.

34 Kiss 1996, 51, 269, Taf. 40/A 139/9; 130/10.

35 Kiss 1996, 52, 269, Taf. 41/A 144/1.

36 Töröк 1994, 12, Taf. 14/15; 30/1.
Kindergräbern von Szebény 1, Grab 183, ${ }^{37}$ Pilismarót-Basaharc, Grab 4, ${ }^{38}$ und Szegvár-Oromdúlö, Grab 682. ${ }^{39}$

Während die meisten Kinder nur eine Glocke mit ins Grab bekamen, nimmt das Mädchen aus Grab 157 aus Vösendorf-Laxenburger Straße mit fünf Glocken innerhalb aller Kindergräber eine einzigartige Stellung ein. Bronzeglocken der Typen 1 /Variante A, Variante B groß und klein, Variante D und der Typen 6 und 7 sind in den Kindergräbern vertreten. An Eisenglocken finden sich die Typen 1/ Variante A und B, Typen 2 und 3 (Tab. 3).

\subsection{Frauenbestattungen mit Glocken}

Aus dem Gräberfeld in Zillingtal sind zwei Frauenbestattungen mit Bronzeglockenfunden bekannt. Es handelt sich um die Gräber D-184 und D-56, ${ }^{40}$ wobei in beiden Fällen die Glocken zwischen den Oberschenkelknochen der Toten lagen. In Grab D-560 lag eine Eisenglocke im Bereich des linken Beckens der Verstorbenen. ${ }^{41}$ In Grab 227 der Nekropole in Sommerein wurde die Glocke bei der linken Schulter aufgefunden. ${ }^{42}$ Ein weiteres Objekt entdeckte man in der Grabverfüllung der Bestattung 12, Kölked-Feketekapu A. ${ }^{43}$ Bei der Verstorbenen aus Grab 216 aus Allatyán-Tulát lag die Bronzeglocke bei der rechten Hand. ${ }^{44}$ Vom Gräberfeld Szeged-Fehértó A ist Grab 253 zu nennen, in dem eine fragmentierte Bronzeglocke am linken Bein des Skelettes aufgefunden wurde. ${ }^{45}$ Eine Frau juvenilen Alters wurde im Grab 26 auf dem Friedhof in der Fehérvári út 149-155, XI. Bezirk, Budapest, entdeckt. Ihre halbkugelige Glocke aus Bronze lag außen am linken Knie, wobei noch eine braune Verfärbung - wahrscheinlich von Leder herstammend - ausgemacht werden konnte. ${ }^{46}$ Gleich drei Gräber mit Glockenfunden stammen aus der Grabung in Budapest, Csepel-Háros Duna-gát, XXI. Bezirk. Grab 1 enthielt eine Bronzeglocke mit einer Kette aus Ringen neben dem linken Oberschenkel. ${ }^{47}$ Bei dem gestörten Grab 21 befand sich die Glocke, die an einer Eisenkette hing, außen beim linken

37 Garam 1975, 84, 104, 108-109, 115, Abb. 14/183/3.

38 FetTich 1965, Taf. 70/10.

39 STADLER 2018 (Szegvár-Oromdúlö in Bilddatenbank Montelius nach G. Lốrinczy), Taf. 264/4.

40 Daim 1998, 100-101, Taf. 6/11. -STAdler 2018 (Zillingtal in Bilddatenbank Montelius nach F. Daim), Taf. 282/20; 167/15.

41 STADLER 2018 (Zillingtal in Bilddatenbank Montelius nach F. Daim), Taf. 599/6.

42 Daim, Lippert 1984, 81, 251, Taf. 116/3.

43 Kiss 1996, 23, 268, Taf. 20/A 12/1.

44 Kovrig 1963, 26, Taf. XVII/65; LXVI/9.

45 Madaras 1995, 40, Taf. 27, Grab 253/2.

46 NAGY 1998, 86; Abb. 35/3, Taf. 79.

47 Sós 1961, 32, 51, Abb. 3/2.-Nagy 1998, 146, Taf. 99/B; 168/10-11. 
Oberschenkelknochen, ${ }^{48}$ und im Grab 19, in dem eine Doppelbestattung - eine adulte Frau mit einem Kind - entdeckt wurde, lag die Bronzeglocke neben dem Schädel der Frau. ${ }^{49}$ Ein weiteres Grab, Grab 241 aus dem Gräberfeld in Tiszafüred, enthielt eine Sargbestattung, wobei ein bronzener Anhänger - wohl eine fragmentierte Glocke - neben dem rechten Becken zu liegen kam. ${ }^{50}$

In Grab 15, Bakonycsernye, das einer reichen adulten Frau gehörte, befand sich ein Bronzeglöckchen zwischen den Oberschenkeln des Skelettes. ${ }^{51}$ Zuletzt sei noch Grab 510 aus dem Gräberfeld in Nové Zámky zu nennen, wo die Glocke gemeinsam mit einem Ring und einem Messer beim linken Oberschenkelknochen der Toten aufgefunden wurde. ${ }^{52}$ Weitere Glockenfunde ohne Angaben der Lage der Glocken in den Gräbern stammen aus Grab 17 von Bačko-Petrovo-Selo, ${ }^{53}$ aus Grab 2 von Balatonfúzfő, ${ }^{54}$ Grab 4 aus Deszk, ${ }^{55}$ den Gräbern 6 und 14 aus der Nekropole in Andocs ${ }^{56}$ und aus Grab 285 in Gátér. ${ }^{57}$ Keine der Frauen bekam mehr als eine Glocke mit ins Grab. Bronzeglocken des Typs 1/Variante A, Variante D und der Typen 2, 3 und 5 sowie Eisenglocken des Typs 1/Variante A, Typ 2 und 4 sind in Frauengräbern vertreten (Tab. 3).

\subsection{Männerbestattungen mit Glocken}

Drei Eisenglocken wurden in Grab 471 des Gräberfeldes Kölked-Feketekapu A in der linken oberen Ecke des Grabes - also auf der rechten Seite oberhalb des Kopfes des Toten - entdeckt. ${ }^{58}$ Im gestörten Männergrab 784 aus der Grabung in der Bogyiszlói út in Szekszárd lag die kleine Bronzeglocke neben der rechten Beckenschaufel des Skeletts. ${ }^{59}$ Ein weiterer Glockenfund stammt aus dem Männergrab 736 aus Szegvár-Oromdúlö. Hier lag das Idiophon beim rechten Unterschenkel. ${ }^{60}$

Glocken ohne Angaben ihrer Lage in den Gräbern kennt man noch aus Pécs-Köztemetô, Grab 45, ${ }^{61}$ aus Budakalász,

48 Sós 1961, 44, 51, Abb. 19/11. - NAGY 1998, 151, Taf. 103/21/5.

49 Sós 1961, 44, 51, Abb. 20/7. - Nagy 1998, 150, Taf. 103/A-B.

50 Garam 1995, 36, Abb. 14, Taf. 11; 77/241/8; $227 / 4$.

51 FÜLÖP 1977, 24, Taf. I/1; II/3.

52 ČILINSKÁ 1966, 99, 201, Taf. 75/510/3.

53 Brukner 1968, Taf. 59/5.

54 Fетtich 1965, 107, Abb. 165/9.

55 Stadler 2018 (Deszk-O. in Bilddatenbank Montelius nach

B. Kürti), Taf. 69/2.

56 Garam 1972, 132, 182, Taf. 3/14; 4/18.

57 KADA 1908, 337.

58 Kiss 1996, 126-127, Abb. 21, Taf. 14/3; 84/4-6.

59 Rosner 1999, 99, Taf. 52; 69/9; 78/7.

60 STADler 2018 (Szegvár-Oromdúlö in Bilddatenbank Montelius nach G. Lőrinczy), Taf. 296/7.

61 Kiss 1977, 96, 101, Taf. 40/1.
Grab 178, ${ }^{62}$ aus Gátér, Grab 73, ${ }^{63}$ und aus Lovćenac (Sekić/ Szeghegy), Grab 1. Hier handelt es sich möglicherweise um eine Reiterbestattung mit Pferd. ${ }^{64}$ In Männergräbern sind die Bronzeglocken der Typen 1/Variante A, Variante B klein und Variante $\mathrm{C}$ sowie Typ 3 vertreten.

Eisenglocken treten nur in einem Grab auf. Es handelt sich um Typ 1/Variante B und Typ 3.

\subsection{Eine Pferdbestattung mit Glocke}

In einem Grab war die Glocke mit einem Pferd assoziiert. Es handelt sich um Grab 119/2 aus dem Gräberfeld von Csákberény-Orondpuszta, in dem sich das Pferd einen Meter rechts von einem menschlichen, weiblichen Skelett befand. Hier lag eine Glocke des Typs 6 beim Schädel des Tieres. ${ }^{65}$ Aus der Awaria sind überhaupt nur ganz wenige Tierbestattungen mit Idiophonen bekannt. Diese wurden bereits im Artikel über Schellenfunde vorgestellt. ${ }^{66}$

\subsection{Bestattungen mit mehr als einem Glockenfund}

In der Regel wurde den Toten eine Glocke mit ins Grab gegeben, nur ganz wenige Bestattete enthielten mehr als eine Glocke. Das Mädchengrab 157 aus Vösendorf-Laxenburger Straße ist mit fünf Bronzeglöckchen an erster Stelle zu nennen. Drei Eisenglocken wurden im Männergrab 471 aus Kölked-Feketekapu A entdeckt. In beiden Gräbern lagen die Glocken auf der rechten Körperseite oberhalb des Kopfes. Jeweils zwei Eisenglocken befanden sich im Männergrab 178 aus Budakalász und in Grab 13 in Gátér. Aus Grab 124 aus Szegvár-Oromdúlö stammen zwei Bronzeglocken. Von keinem der letztgenannten Gräber sind genaue Angaben über die Lage der Glocken publiziert.

\subsection{Zur Lage der Glocken in den Gräbern}

Glocken wurden vor allem im Bereich von Becken, Oberschenkeln, Beinen, Unterarmen und Händen entdeckt. Bedenkt man, dass die Toten in gestreckter Rückenlage mit gestreckten Armen beigesetzt wurden, so ist als bevorzugte Lage der Glocken der Bereich vom Becken bis zu den Knien festzustellen, was wiederum als Hinweis für das Tragen der Glocken an Bändern, Ketten oder in Behältnissen am Gürtel dienen könnte. Ähnliche Tragweisen wurden schon für Schellenfunde festgestellt. ${ }^{67}$

62 Stadler 2018 (Budakalász in Bilddatenbank Montelius nach T. Vida), Taf. 24/3-4.

63 KADA 1905, 384.

64 Hampel 1905, Bd. II, 843, Bd. III, Taf. 497/d/1. - VINSKi 1958, 60, Taf. 7/25. - Gere 1998, 52, Taf. 6/1.

65 LÁszló 2015, 59, 104, Taf. 10/119/2/6; 58/119/2/1.

66 Pomberger, Stadler 2018.

67 Pomberger, Stadler 2018, 129. 


\begin{tabular}{|c|c|c|c|c|c|c|c|c|c|c|c|c|c|}
\hline 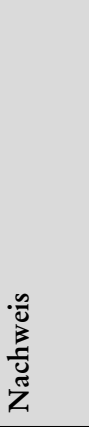 & 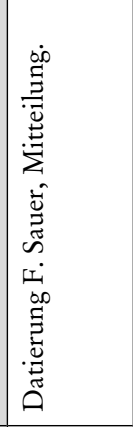 & 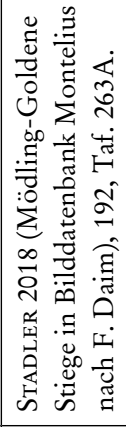 & 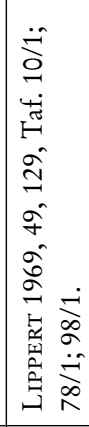 & 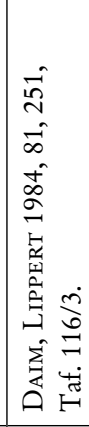 & 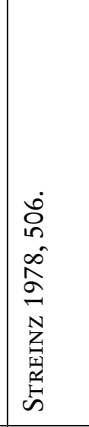 & 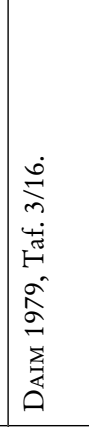 & 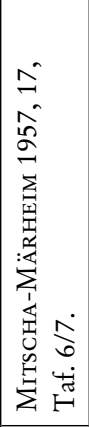 & 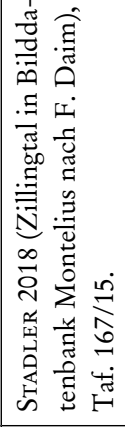 & 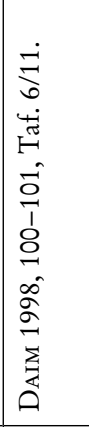 & 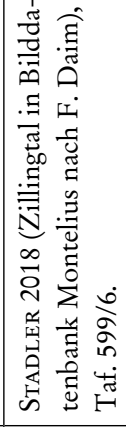 & 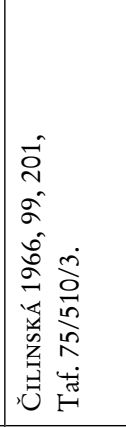 & 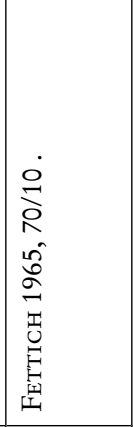 & 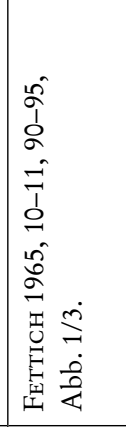 \\
\hline 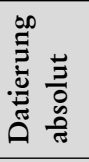 & 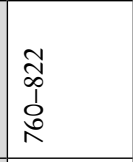 & \begin{tabular}{|l}
$\tilde{3}$ \\
0 \\
0 \\
0 \\
0 \\
0 \\
\end{tabular} & $\begin{array}{l}\widetilde{1} \\
\infty \\
0 \\
o \\
o \\
0 \\
\end{array}$ & 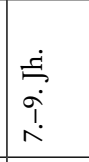 & n. & n. & \begin{tabular}{|l}
$\tilde{i}$ \\
$\infty$ \\
0 \\
0 \\
$o$ \\
0 \\
0
\end{tabular} & $\begin{array}{l}0 \\
0 \\
0 \\
1 \\
0 \\
0 \\
\end{array}$ & \begin{tabular}{|l}
0 \\
0 \\
1 \\
1 \\
0 \\
0 \\
\end{tabular} & \begin{tabular}{|l}
0 \\
0 \\
0 \\
1 \\
0 \\
0 \\
\end{tabular} & 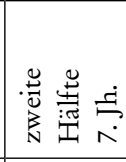 & $\begin{array}{l}\dot{E} \\
\vec{i} \\
\dot{b} \\
\end{array}$ & 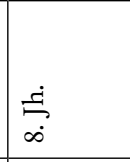 \\
\hline 足 & \begin{tabular}{l}
$\Xi$ \\
\multirow{\Delta}{\Delta}{} \\
$\tilde{\omega}$
\end{tabular} & 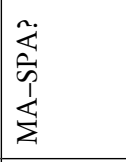 & $\underset{\omega}{\overleftarrow{\omega}}$ & 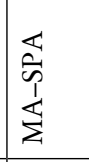 & n. & . & $\frac{\dot{4}}{\hat{\omega}}$ & 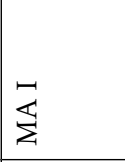 & 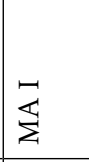 & $\sum_{\Sigma}$ & 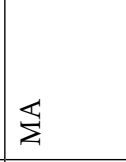 & 崖 & 这 \\
\hline 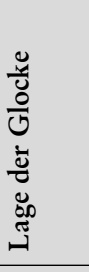 & 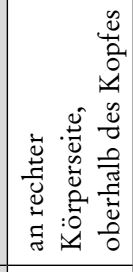 & 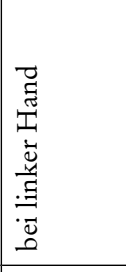 & 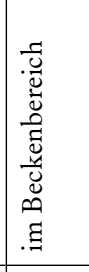 & 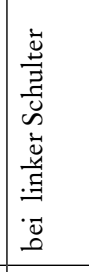 & 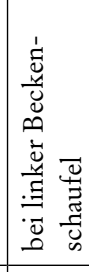 & $\stackrel{\dot{4}}{\check{i}}$ & 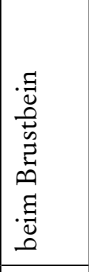 & 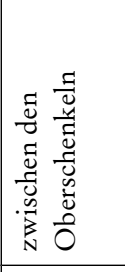 & 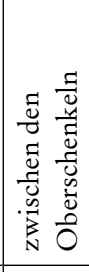 & 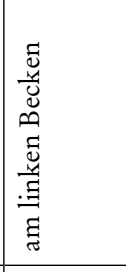 & 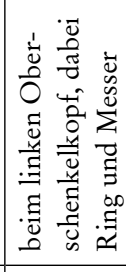 & $\begin{array}{l}\dot{4} \\
\dot{4}\end{array}$ & $\begin{array}{l}\dot{\Delta} \\
\dot{4}\end{array}$ \\
\hline 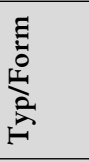 & 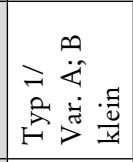 & 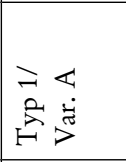 & 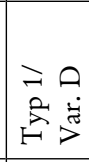 & 常 & o. & 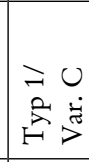 & $\underset{n}{+}$ & n & 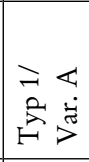 & 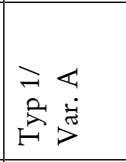 & 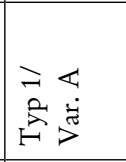 & 足 & 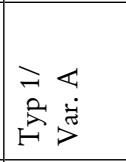 \\
\hline 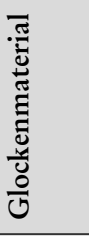 & 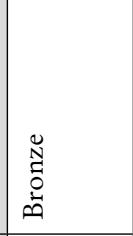 & 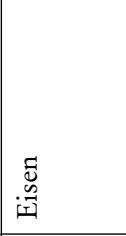 & $\begin{array}{l}\tilde{N} \\
\tilde{D} \\
\stackrel{0}{0}\end{array}$ & 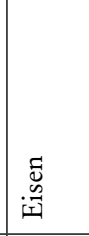 & $\begin{array}{l}\tilde{N} \\
\tilde{D} \\
. \\
0\end{array}$ & \begin{tabular}{|l}
$\tilde{N}$ \\
$\tilde{D}$ \\
0 \\
0
\end{tabular} & 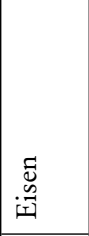 & $\begin{array}{l}0 \\
N \\
0 \\
0 \\
0 \\
0\end{array}$ & $\begin{array}{l}\mathscr{N} \\
\stackrel{N}{0} \\
\stackrel{0}{n}\end{array}$ & 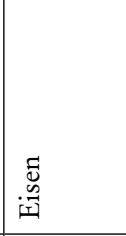 & 苂 & 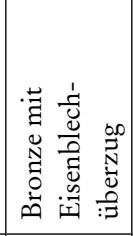 & Ñ \\
\hline $\begin{array}{l}5 \\
\frac{5}{0} \\
\frac{\tilde{L}}{0}\end{array}$ & in & - & - & - & - & - & - & - & - & - & - & - & - \\
\hline 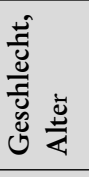 & 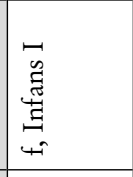 & 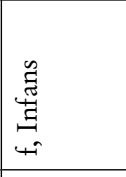 & 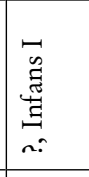 & $\cong$ & n. & , & n. & 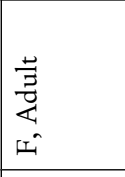 & 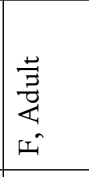 & 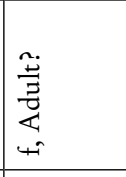 & 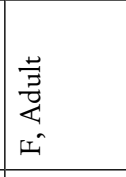 & 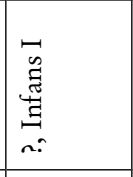 & I \\
\hline 苛 & in & 芦 & $\overrightarrow{\tilde{\lambda}}$ & సิ & 今 & 离 & in & م⿱⺈ & $\begin{array}{l}+ \\
\vec{D} \\
\vec{D}\end{array}$ & 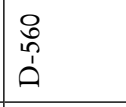 & in & t & 离 \\
\hline 窇 & 足 & 占 & 安 & 占 & 足 & 占 & 岁 & 岁 & 桌 & 点 & 恙 & 号 & 旁 \\
\hline 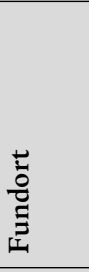 & 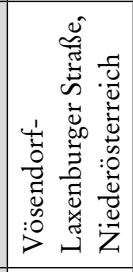 & 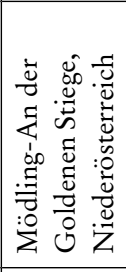 & 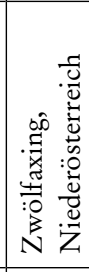 & 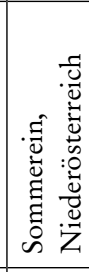 & 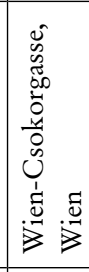 & 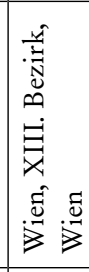 & 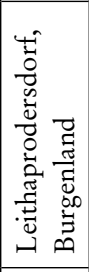 & 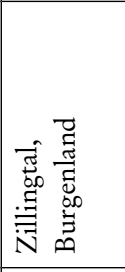 & 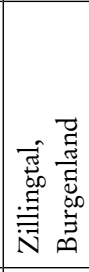 & 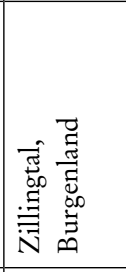 & 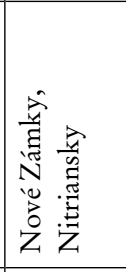 & 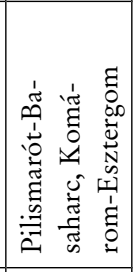 & 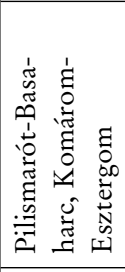 \\
\hline 竞 & - & $N$ & $m$ & t & in & 0 & $n$ & $\infty$ & $\infty$ & $\infty$ & $a$ & 으 & 우 \\
\hline
\end{tabular}




\begin{tabular}{|c|c|c|c|c|c|c|c|c|c|c|c|c|c|}
\hline 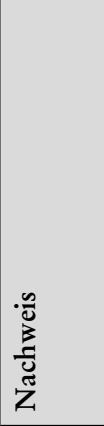 & 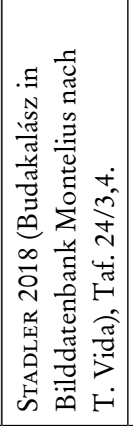 & 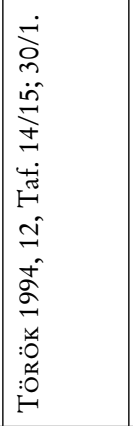 & 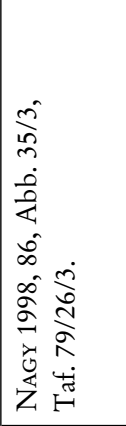 & 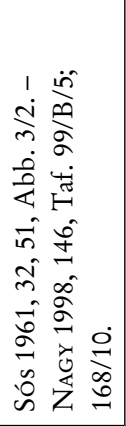 & 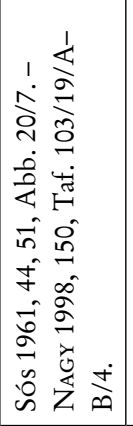 & 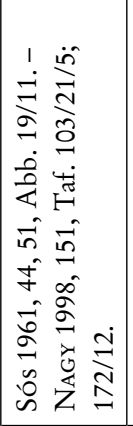 & 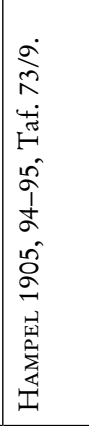 & 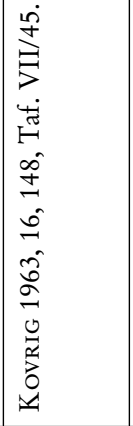 & 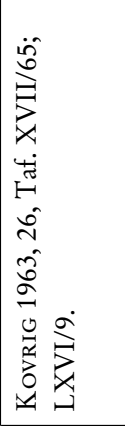 & 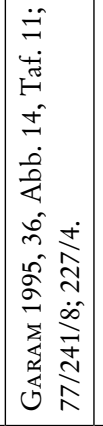 & 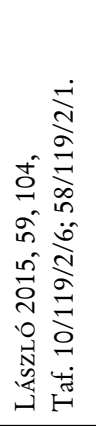 & 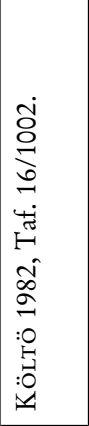 & 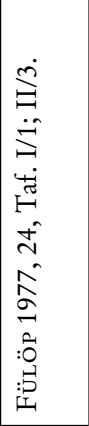 \\
\hline 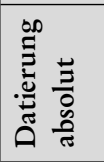 & $\begin{array}{l}0 \\
0 \\
0 \\
0 \\
0 \\
i n\end{array}$ & 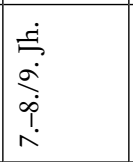 & $\begin{array}{l}\text { Iี } \\
0 \\
0 \\
o \\
0 \\
0\end{array}$ & $\begin{array}{l}0 \\
0 \\
0 \\
0 \\
0 \\
0 \\
i n\end{array}$ & 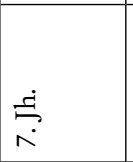 & $\begin{array}{l}\text { I } \\
0 \\
0 \\
0 \\
0\end{array}$ & $\begin{array}{l}\dot{a} \\
\dot{\hat{i}} \\
\dot{b}\end{array}$ & $\begin{array}{l}0 \\
0 \\
1 \\
0 \\
0 \\
0\end{array}$ & $\begin{array}{l}0 \\
0 \\
1 \\
0 \\
0 \\
3\end{array}$ & 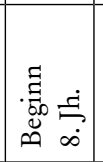 & $\begin{array}{l}\dot{E} \\
\grave{i} \\
\dot{b}\end{array}$ & n. & $\begin{array}{l}\tilde{Z} \\
0 \\
0 \\
0 \\
0 \\
0\end{array}$ \\
\hline 章 & 离 & 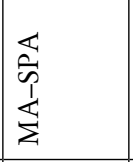 & 岕 & $\overleftrightarrow{\Psi}$ & 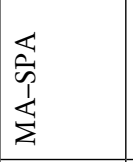 & $\stackrel{\overleftarrow{n}}{\hat{n}}$ & 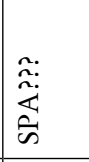 & $\sum_{\Sigma}$ & $\sum_{\Sigma}$ & $\overleftrightarrow{\tilde{n}}$ & $\overleftrightarrow{\Psi}$ & n. & 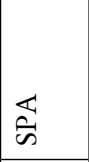 \\
\hline 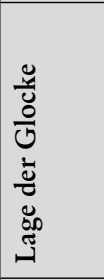 & $\dot{\square}$ & 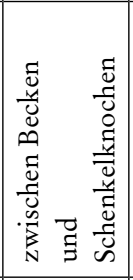 & 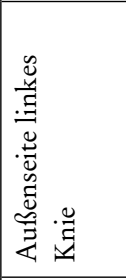 & 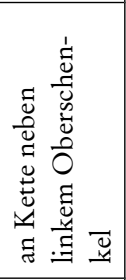 & 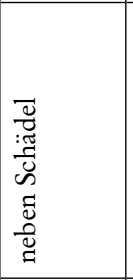 & 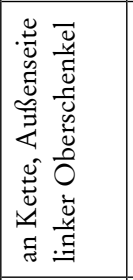 & $\dot{\longleftrightarrow}$ & 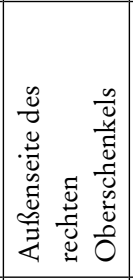 & 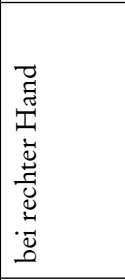 & 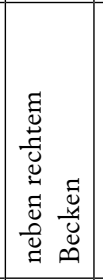 & 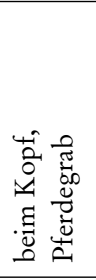 & \begin{tabular}{|l}
$\dot{4}$ \\
\end{tabular} & 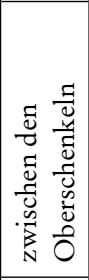 \\
\hline 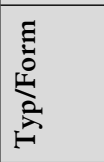 & $\underset{n}{m}$ & 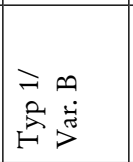 & 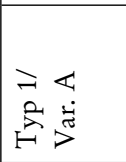 & $\underset{H}{N}$ & 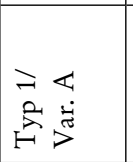 & 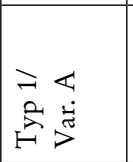 & 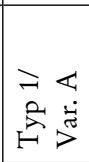 & 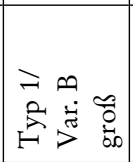 & 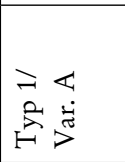 & s. & 点 & 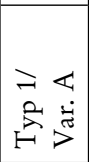 & 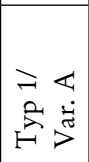 \\
\hline 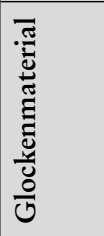 & 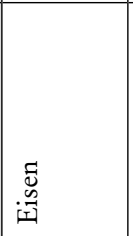 & 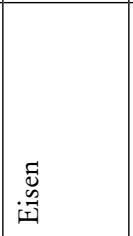 & 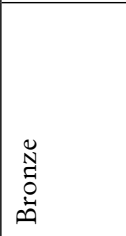 & 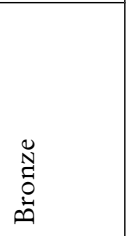 & $\begin{array}{l}0 \\
\tilde{N} \\
0 \\
0 \\
0\end{array}$ & 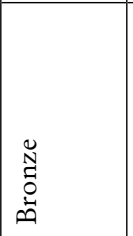 & 苂 & 苂 & 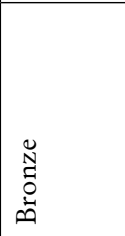 & 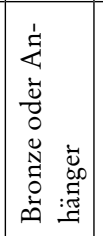 & 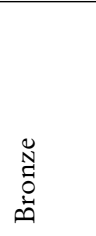 & 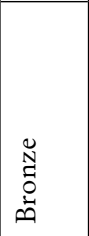 & 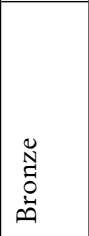 \\
\hline 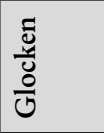 & 4 & - & - & - & - & - & - & - & - & - & - & - & - \\
\hline 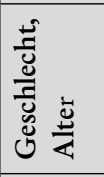 & $\begin{array}{l}n . \\
\varepsilon\end{array}$ & 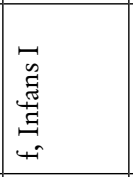 & 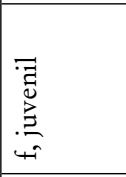 & \begin{tabular}{|l}
$\frac{3}{3}$ \\
$\frac{3}{4}$ \\
4 \\
4
\end{tabular} & 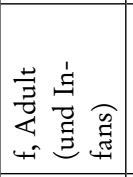 & 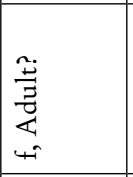 & , & 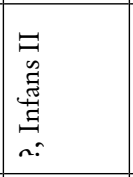 & $\begin{array}{l}\frac{4}{3} \\
\frac{3}{4} \\
4 \\
4\end{array}$ & \begin{tabular}{|l}
4 \\
\\
3 \\
$\vdots$ \\
4 \\
4
\end{tabular} & 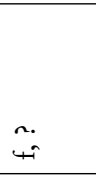 & I & \begin{tabular}{|l}
5 \\
3 \\
3 \\
4 \\
5 \\
5
\end{tabular} \\
\hline ड़ّ̆ & $\stackrel{\infty}{\beth}$ & $\approx$ & i & - & $\stackrel{2}{ }$ & $\vec{\lambda}$ & 离苛泀 & $\infty$ & $\stackrel{0}{\sim}$ & $\vec{J}$ & $\frac{9}{2}$ & 咅营 & $\stackrel{2}{2}$ \\
\hline ت్ & 萤 & 学 & 萤 & 总 & 总 & 号 & 学 & 号 & 号 & 旁 & 总 & 号 & 总 \\
\hline 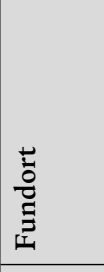 & 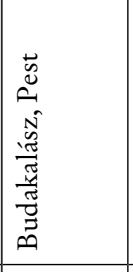 & 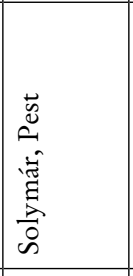 & 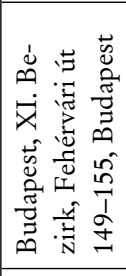 & 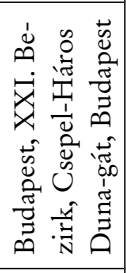 & 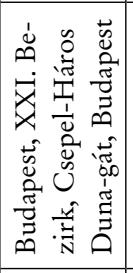 & 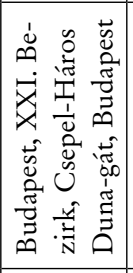 & 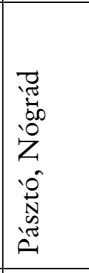 & 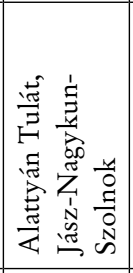 & 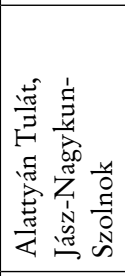 & 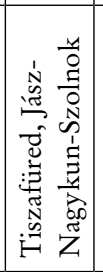 & 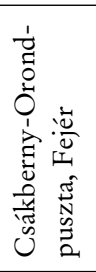 & 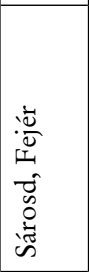 & 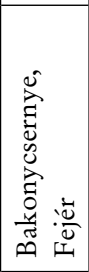 \\
\hline 槖 & $=$ & $\approx$ & $\approx$ & \pm & \pm & \pm & $\stackrel{2}{\sim}$ & $\stackrel{0}{2}$ & $\stackrel{2}{2}$ & $\approx$ & $\stackrel{\infty}{\sim}$ & $\approx$ & i \\
\hline
\end{tabular}




\begin{tabular}{|c|c|c|c|c|c|c|c|c|c|c|c|c|c|}
\hline 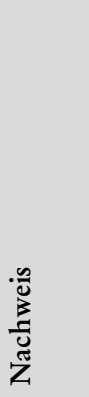 & 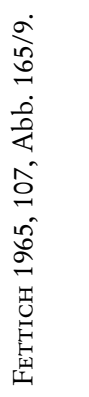 & 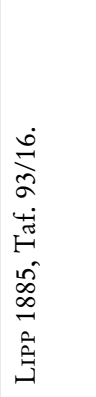 & 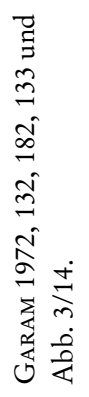 & 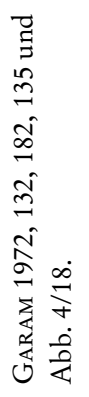 & 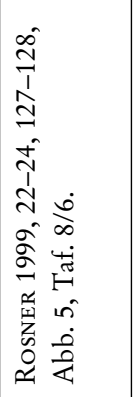 & 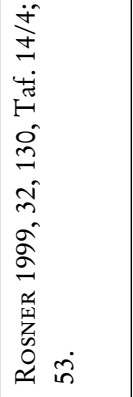 & 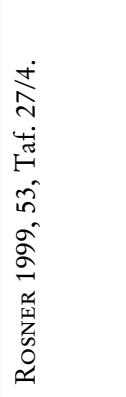 & 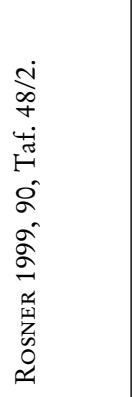 & 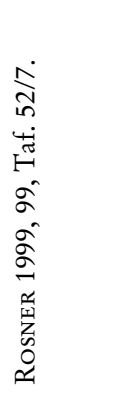 & 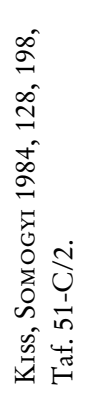 & 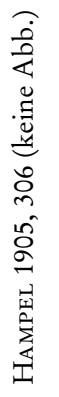 & 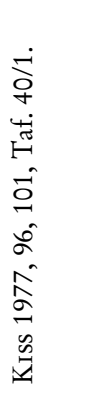 & 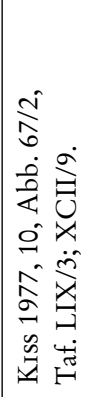 \\
\hline 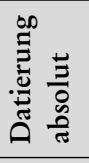 & $\begin{array}{l}0 \\
0 \\
0 \\
\infty \\
0 \\
1 \\
\end{array}$ & n. & 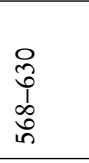 & 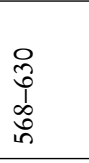 & 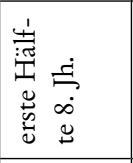 & 齐 & $\begin{array}{l}0 \\
0 \\
0 \\
0 \\
0 \\
0 \\
0\end{array}$ & $\begin{array}{l}0 \\
0 \\
0 \\
0 \\
0 \\
0 \\
0\end{array}$ & $\frac{\dot{E}}{\stackrel{\dot{E}}{\hat{\sigma}}}$ & $\begin{array}{l}\dot{\Xi} \\
\stackrel{a}{i} \\
\grave{n}\end{array}$ & n. & 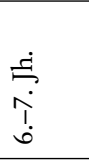 & $\begin{array}{l}\tilde{Z} \\
0 \\
0 \\
0 \\
0 \\
0\end{array}$ \\
\hline 离 & 応 & n. & 左 & 庒 & 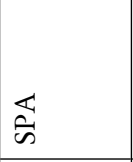 & 岕 & 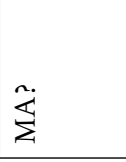 & $\stackrel{\dot{\Sigma}}{\Sigma}$ & 忿 & 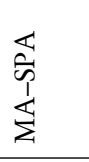 & n. & 応 & $\overleftarrow{\hbar}$ \\
\hline 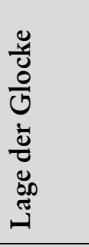 & $\stackrel{\dot{\leftrightarrow}}{\ddot{4}}$ & $\underset{\Delta}{\dot{\Delta}}$ & $\begin{array}{l}\dot{\Delta} \\
\ddot{~}\end{array}$ & $\dot{\leftrightarrow}$ & 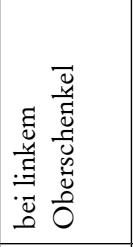 & 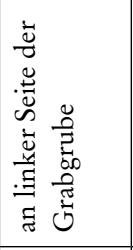 & 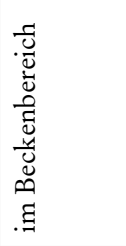 & 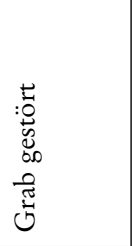 & 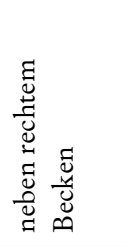 & 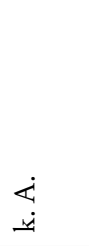 & 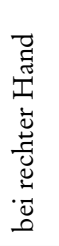 & $\stackrel{\leftrightarrow}{\dot{\Delta}}$ & 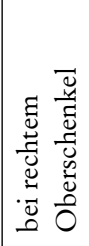 \\
\hline 吝 & $\stackrel{N}{2}$ & ma & 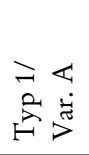 & 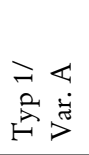 & $\underset{n}{2}$ & $\underset{n}{2}$ & 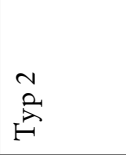 & $\hat{\hat{z}}$ & in & 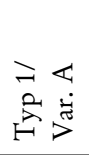 & n. & 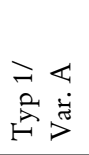 & 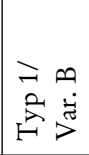 \\
\hline 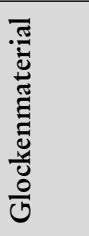 & 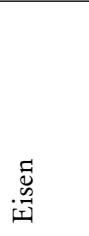 & $\begin{array}{l}\text { 㤩 } \\
\text { 离 }\end{array}$ & 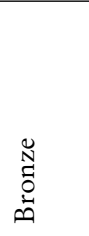 & 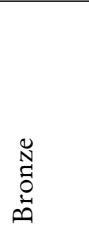 & 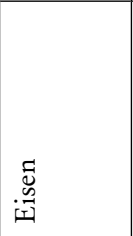 & 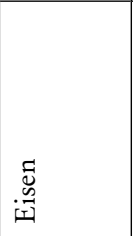 & 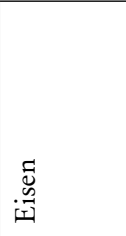 & $\begin{array}{l}\mathscr{N} \\
\stackrel{0}{0} \\
\stackrel{0}{0.0}\end{array}$ & $\begin{array}{l}\tilde{N} \\
\stackrel{0}{0} \\
\stackrel{0}{0.0}\end{array}$ & 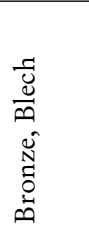 & 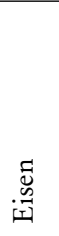 & $\begin{array}{l}\tilde{N} \\
\stackrel{0}{0} \\
\stackrel{0}{n}\end{array}$ & 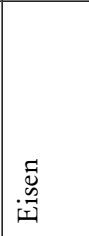 \\
\hline $\begin{array}{l}\frac{5}{5} \\
\frac{\tilde{c}}{0} \\
\text { U. } \\
\end{array}$ & - & - & - & - & - & - & - & - & - & - & - & - & - \\
\hline 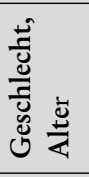 & $\stackrel{\pi}{*}$ & 1 & 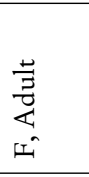 & $\stackrel{.}{\leftrightarrow}$ & 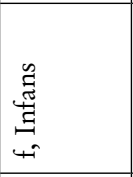 & 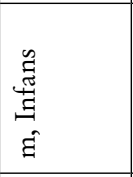 & 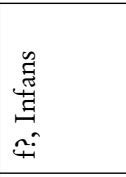 & 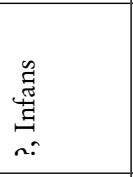 & 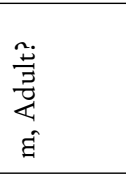 & n. & $\begin{array}{l}\frac{3}{3} \\
\frac{\vec{E}}{4} \\
n \\
n\end{array}$ & 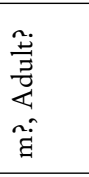 & 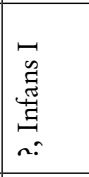 \\
\hline 芯 & N & 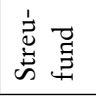 & 0 & \pm & $\stackrel{\infty}{0}$ & $\bar{\sigma}$ & 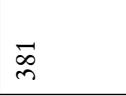 & $\stackrel{\infty}{N}$ & $\underset{\substack{ \pm \wedge}}{\wedge}$ & $\overrightarrow{\dot{\pi}}$ & $\stackrel{\alpha}{\sigma}$ & in & + \\
\hline ت્ّ & 号 & 学 & 号 & 号 & 总 & 兄 & 号 & 号 & 号 & 号 & 号 & 兄 & 号 \\
\hline 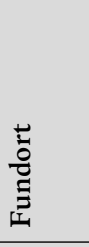 & 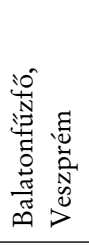 & 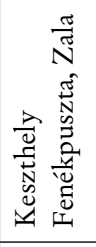 & 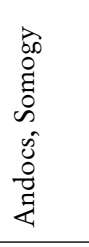 & 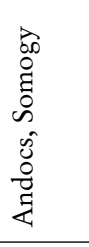 & 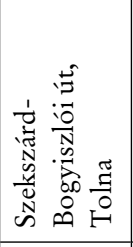 & 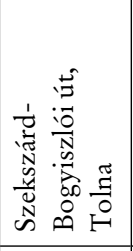 & 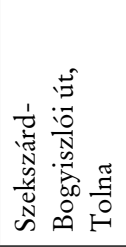 & 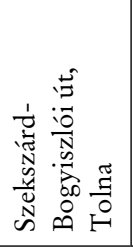 & 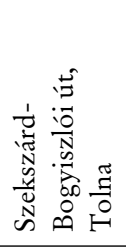 & 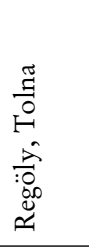 & 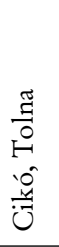 & 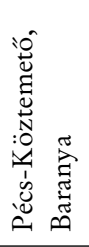 & 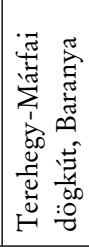 \\
\hline ن & $\bar{\sim}$ & $\tilde{\lambda}$ & $\tilde{\sim}$ & $\tilde{\sim}$ & $\stackrel{ \pm}{\sim}$ & $\underset{\sim}{ \pm}$ & $\stackrel{ \pm}{\sim}$ & $\stackrel{ \pm}{\sim}$ & $\stackrel{ \pm}{\sim}$ & $\stackrel{\mathscr{\sim}}{\sim}$ & $\stackrel{\sim}{\sim}$ & $\hat{\lambda}$ & $\stackrel{\infty}{\sim}$ \\
\hline
\end{tabular}




\begin{tabular}{|c|c|c|c|c|c|c|c|c|c|c|c|c|}
\hline 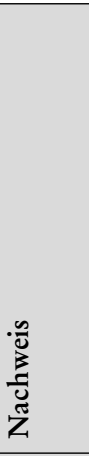 & 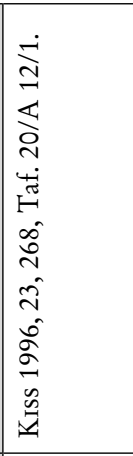 & 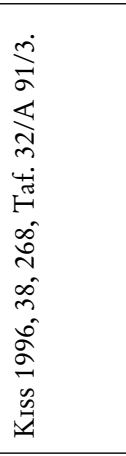 & 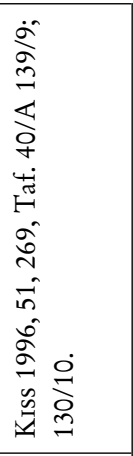 & 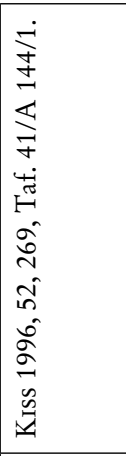 & 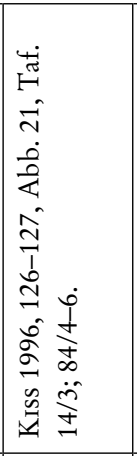 & 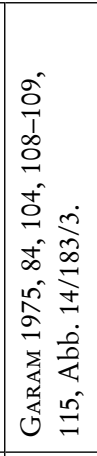 & 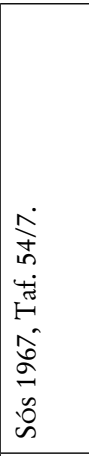 & 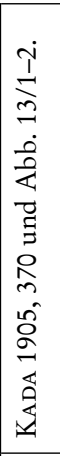 & 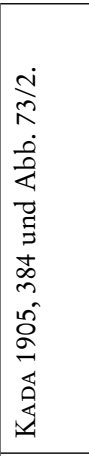 & 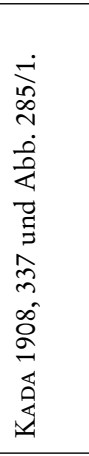 & 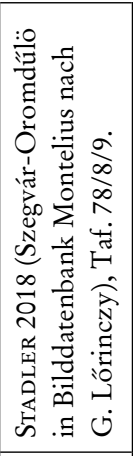 & 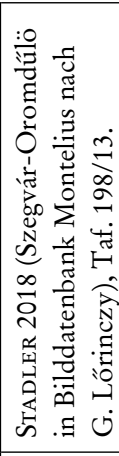 \\
\hline 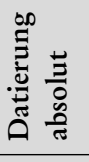 & \begin{tabular}{|l}
0 \\
0 \\
0 \\
0 \\
0 \\
$i$ \\
$n$
\end{tabular} & $\begin{array}{l}0 \\
\hat{\zeta} \\
1 \\
\infty \\
i \\
\text { n̂ }\end{array}$ & $\begin{array}{l}0 \\
\hat{0} \\
0 \\
\infty \\
i \\
n\end{array}$ & \begin{tabular}{|l}
0 \\
0 \\
0 \\
0 \\
$\infty$ \\
$i$ \\
$n$
\end{tabular} & \begin{tabular}{|l}
0 \\
0 \\
0 \\
0 \\
0 \\
$i$ \\
$n$
\end{tabular} & 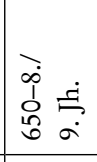 & o. & 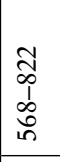 & $\begin{array}{l}0 \\
0 \\
0 \\
\infty \\
i \\
i n \\
\end{array}$ & 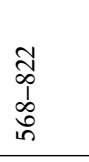 & $\begin{array}{l}0 \\
0 \\
0 \\
0 \\
0 \\
i n \\
\end{array}$ & 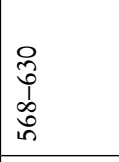 \\
\hline 足 & 左 & 死 & 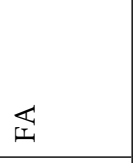 & 丝 & 左 & 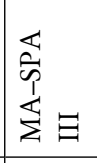 & n. & 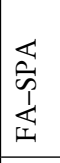 & 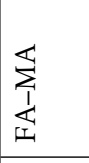 & 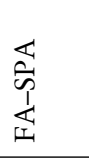 & 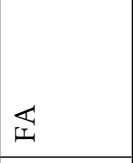 & 医 \\
\hline 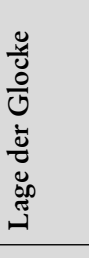 & 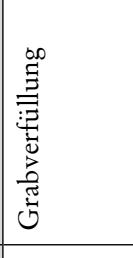 & 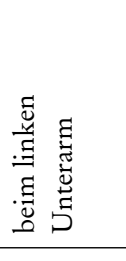 & 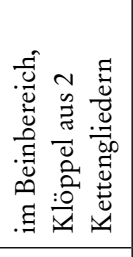 & 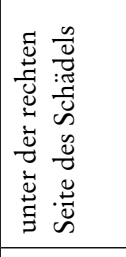 & 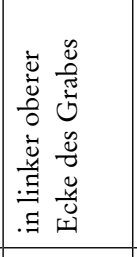 & ¿ & 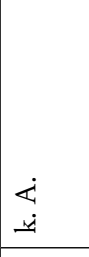 & $\stackrel{\dot{\Delta}}{\Perp}$ & $\stackrel{\Delta}{\Perp}$ & $\begin{array}{l}\dot{\Delta} \\
\Perp\end{array}$ & ¿ & $\begin{array}{l}\dot{\Delta} \\
\ddot{4}\end{array}$ \\
\hline ڤ్ & 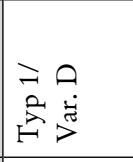 & 常 & 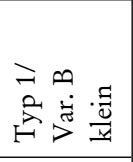 & 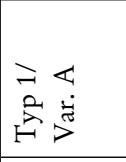 & 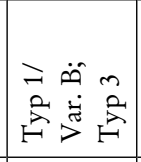 & s. & 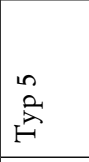 & 点 & 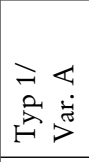 & 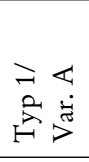 & 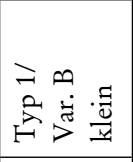 & 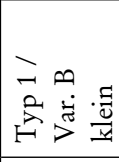 \\
\hline 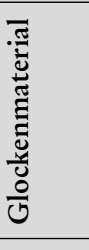 & $\begin{array}{l}0 \\
\tilde{N} \\
0 \\
.0 \\
\end{array}$ & $\begin{array}{l}0 \\
N \\
0 \\
0 \\
0 \\
0\end{array}$ & $\begin{array}{l}0 \\
\tilde{N} \\
0 \\
0 \\
0\end{array}$ & 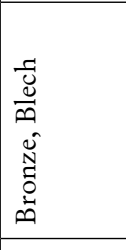 & 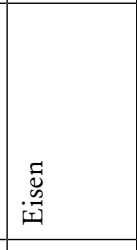 & 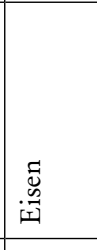 & \begin{tabular}{|l}
0 \\
$N$ \\
0 \\
0 \\
0 \\
0
\end{tabular} & 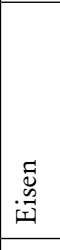 & 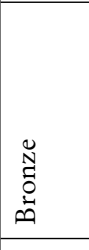 & \begin{tabular}{|l}
0 \\
$\tilde{N}$ \\
0 \\
0 \\
0 \\
\end{tabular} & $\begin{array}{l}0 \\
N \\
0 \\
0 \\
0 \\
\end{array}$ & 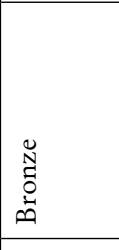 \\
\hline 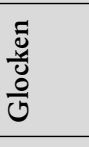 & - & - & - & - & $m$ & - & $\rightarrow$ & N & - & - & n & - \\
\hline 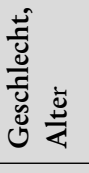 & 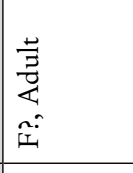 & 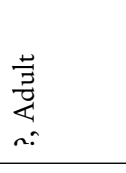 & 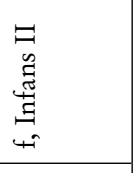 & 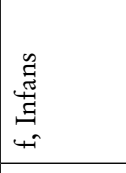 & 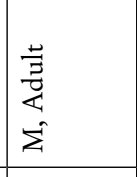 & 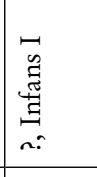 & 1 & n. & $\begin{array}{l}\frac{3}{3} \\
\frac{\vec{z}}{4} \\
\dot{\Sigma} \\
\dot{\Sigma}\end{array}$ & 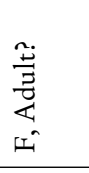 & n. & n. \\
\hline छัّँ & $\approx$ & $\sigma$ & & $\underset{⿱}{ \pm}$ & $\bar{F}$ & $\stackrel{\infty}{\infty}$ & 咅 & $\stackrel{2}{2}$ & $\Re$ & $\begin{array}{l}\mathscr{\infty} \\
\stackrel{\infty}{N} \\
\end{array}$ & $\stackrel{ \pm}{\beth}$ & 文 \\
\hline 节 & 号 & 号 & 号 & 足 & 号 & 号 & 号 & 号 & 㣽 & 号 & Z & 莡 \\
\hline 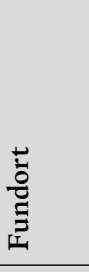 & 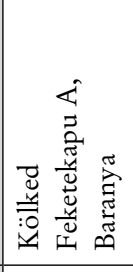 & 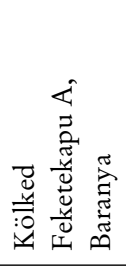 & 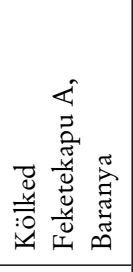 & 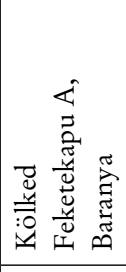 & 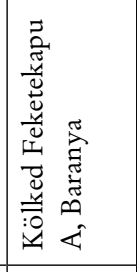 & 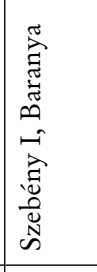 & 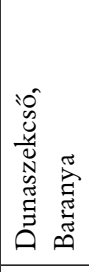 & 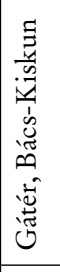 & 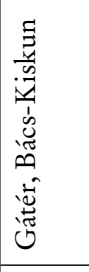 & 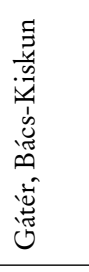 & 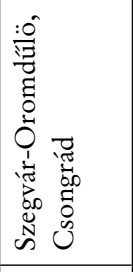 & 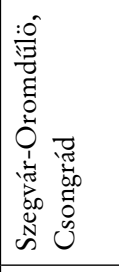 \\
\hline 壹 & ते & ते & $\hat{\mathrm{N}}$ & ते & సे & m & $\vec{m}$ & $\tilde{m}$ & లె & $\approx$ & $\tilde{m}$ & $m$ \\
\hline
\end{tabular}




\begin{tabular}{|c|c|c|c|c|c|c|c|c|c|c|c|c|}
\hline $\begin{array}{l}\frac{n}{\pi} \\
\overline{\tilde{n}} \\
\bar{u} \\
\tilde{\pi} \\
\end{array}$ & 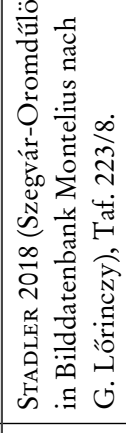 & 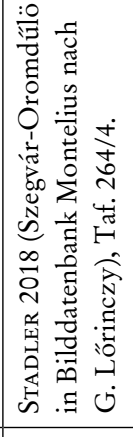 & 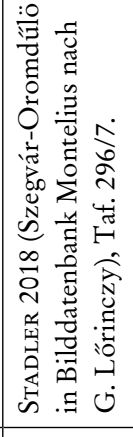 & 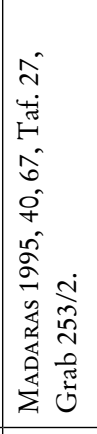 & 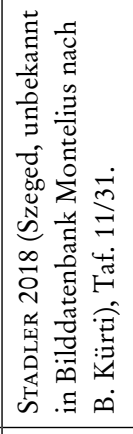 & 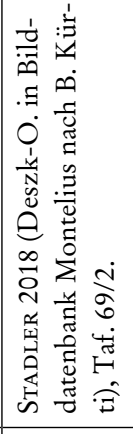 & 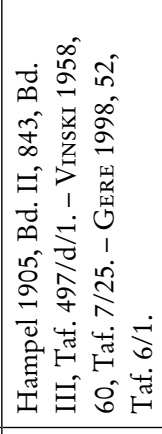 & 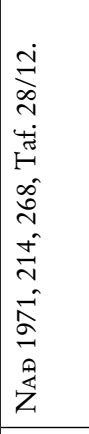 & 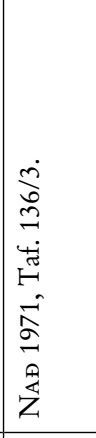 & 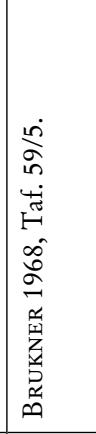 & 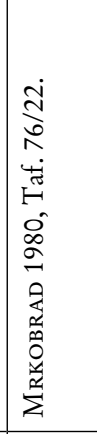 & 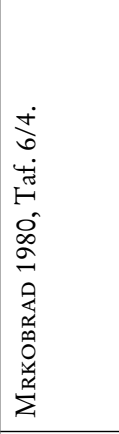 \\
\hline 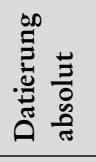 & 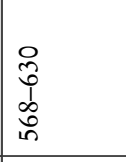 & 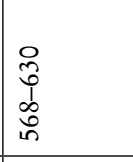 & $\begin{array}{l}\tilde{0} \\
\hat{0} \\
0 \\
0 \\
0 \\
i n\end{array}$ & $\begin{array}{l}0 \\
0 \\
0 \\
1 \\
0 \\
0 \\
1 \\
\end{array}$ & n. & $\begin{array}{l}\dot{\vec{\hbar}} \\
\stackrel{\infty}{\infty} \\
\stackrel{\infty}{\circ}\end{array}$ & $\begin{array}{l}0 \\
0 \\
0 \\
1 \\
0 \\
0\end{array}$ & 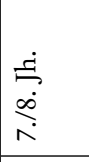 & n. & \begin{tabular}{|l|}
0 \\
0 \\
0 \\
0 \\
0 \\
0 \\
$i n$ \\
\end{tabular} & n. & n. \\
\hline 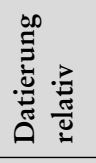 & 医 & 医 & 离 & 左 & n. & 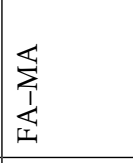 & $\underset{⿱ 乛 龰}{E}$ & 这 & n. & 左 & n. & n. \\
\hline 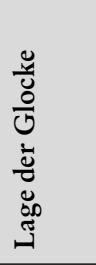 & 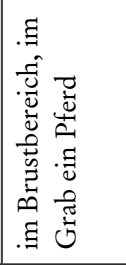 & 这 & 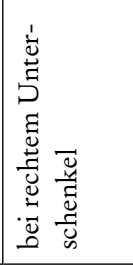 & 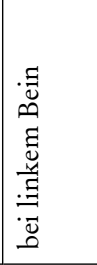 & $\stackrel{\dot{4}}{\ddot{4}}$ & $\dot{4}$ & 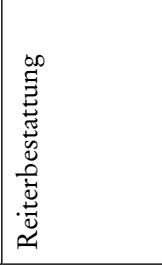 & $\underset{\dot{4}}{\dot{\alpha}}$ & $\stackrel{\dot{4}}{\ddot{4}}$ & 迅 & $\stackrel{\dot{4}}{\ddot{4}}$ & $\stackrel{\dot{4}}{\ddot{4}}$ \\
\hline 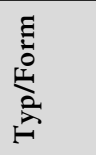 & 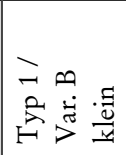 & 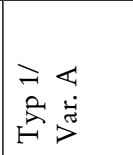 & 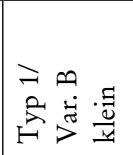 & 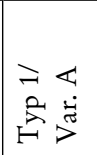 & 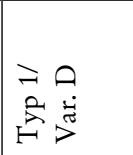 & 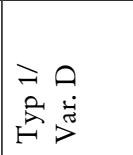 & 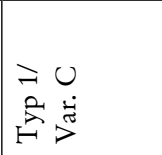 & 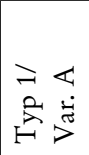 & 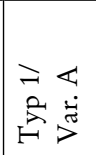 & 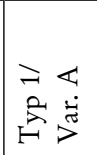 & 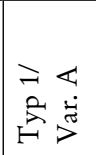 & 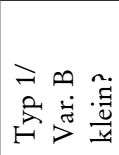 \\
\hline 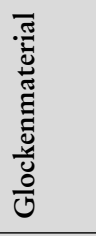 & $\begin{array}{l}\tilde{N} \\
\tilde{D} \\
. \\
.0\end{array}$ & 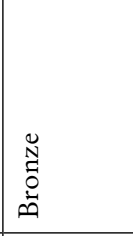 & 苂 & 苂 & $\begin{array}{l}\tilde{N} \\
\tilde{N} \\
\stackrel{0}{0} \\
.0\end{array}$ & $\begin{array}{l}\tilde{N} \\
\tilde{D} \\
0 \\
0 \\
0\end{array}$ & 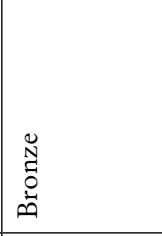 & 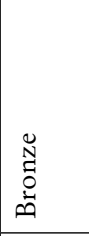 & 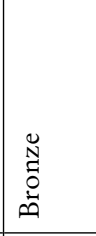 & $\begin{array}{l}\tilde{N} \\
\stackrel{N}{0} \\
\stackrel{0}{n} \\
\end{array}$ & 苂 & 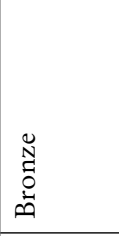 \\
\hline 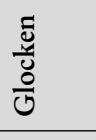 & - & - & - & - & - & - & - & - & - & - & - & - \\
\hline 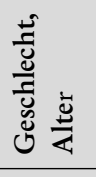 & 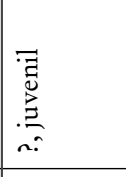 & 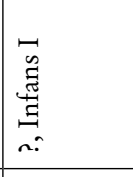 & 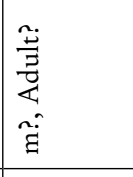 & 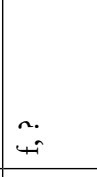 & ' & 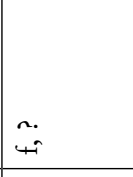 & 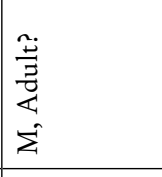 & \begin{tabular}{|l}
$\frac{3}{3}$ \\
$\frac{3}{4}$ \\
$\Sigma$ \\
$\Sigma$
\end{tabular} & ' & 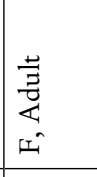 & & ' \\
\hline 芯艺 & $\begin{array}{l}\text { O } \\
\text { in } \\
\end{array}$ & 周 & $\stackrel{2}{\curvearrowright}$ & $\stackrel{\text { }}{\sim}$ & 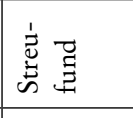 & $\theta$ & - & 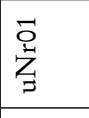 & 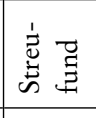 & $\approx$ & 咅 & 离苛 \\
\hline 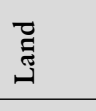 & 号 & 兄 & 号 & 忿 & 号 & 号 & 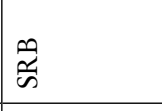 & 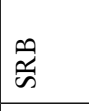 & 站 & 卷 & $\begin{array}{l}\tilde{*} \\
\text { జे }\end{array}$ & 光 \\
\hline 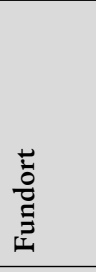 & 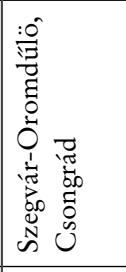 & 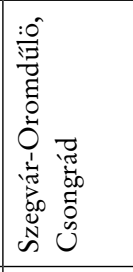 & 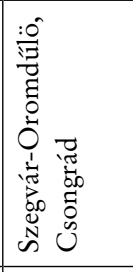 & 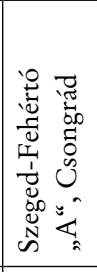 & 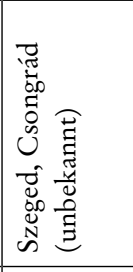 & 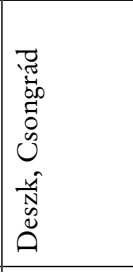 & 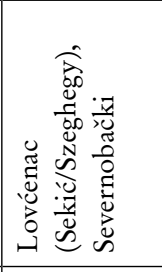 & 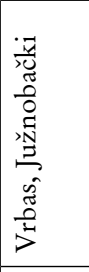 & 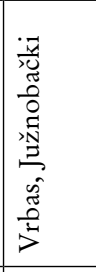 & 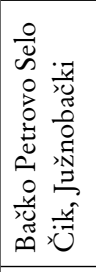 & 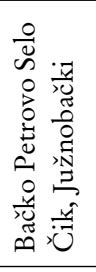 & 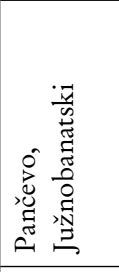 \\
\hline 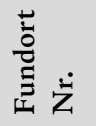 & $\tilde{m}$ & $\tilde{m}$ & $\tilde{m}$ & $\stackrel{ \pm}{m}$ & $\stackrel{m}{m}$ & ల్ల & $\hat{m}$ & $\left.\right|_{m} ^{\infty}$ & $\stackrel{\infty}{\infty}$ & m & mे & q \\
\hline
\end{tabular}


Manche Idiophone wurden beim Brustbein, beim Schädel oder im Schulterbereich aufgefunden. Hier wurde die Glocke wahrscheinlich als Halsschmuck getragen. Rätsel gibt die Interpretation der Lage der Glocken auf der rechten Seite oberhalb des Kopfes der Toten auf. Für Grab 157, Vösendorf-Laxenburger Straße, oberhalb des Kopfes auf der rechten Seite, wird angenommen, dass die fünf Glöckchen in einem Säckchen oder einer Tasche ins Grab gelegt wurden.

\section{Schlussfolgerung, Ausblick}

Im Prinzip wurden nur ganz wenige Personen in der Awaria mit Glocken bestattet: Frauen stehen hier an erster Stelle, gefolgt von Kindern und Männern. Daher kann angenommen werden, dass Glocken bei der Bevölkerung des Khaganats keine große Rolle gespielt haben.

In frühawarischer Zeit findet man mit 25 Stück noch die meisten Glocken, in den anderen Perioden sinkt ihre Zahl auf weniger als die Hälfte. Jedoch kommen ab der mittelawarischen Periode Bronze- und Eisenschellen in Gebrauch, und diese treten in Folge häufig auf. Glocken werden folglich von Schellen abgelöst. Bedenkt man, dass in der Spätantike viele Glocken und Glöckchen im täglichen Leben eine nicht wegzudenkende Rolle als Amulette gespielt haben, so dürfte dieser Brauch in frühawarischer Zeit nur von ganz wenigen Bevölkerungsgruppen weitertradiert worden sein. Glockenfunde in antiker Zeit wurden noch nicht ausreichend auf ihre Funktion untersucht, dürften aber vermutlich - wenn eine Person sie täglich mit sich herumtrug - einen amulettartigen, apotropäischen Charakter gehabt haben. Dies ist auch für die Glockenfunde in awarischen Gräbern vorstellbar. Die Glocken wurden vorwiegend am Gürtel in einem Behältnis oder an einer Kette oder einem Band getragen. In vereinzelten Fällen dienten sie als Halsschmuck.

Während die meisten Bestatteten eine Glocke aufwiesen, stechen das Mädchengrab aus Vösendorf-Laxenburger Straße mit fünf Bronzeglöckchen und das Männergrab 471 aus Kölked-Feketekapu A mit drei Eisenglocken, die alle rechts oberhalb der Schädels aufgefunden wurden, hervor. Drei der fünf Bronzeglöckchen ergeben sogar einen Dreiklang, gestört von der vierten Glocke, die zur Quint in einer Sekund erklingt. Die Glockentypologie und ihr Vergleich mit Vorgängern aus früheren Zeiten weist im Khaganat mehr auf römisch-antiken als auf östlichen Ursprung hin, denn nur drei Typen dürften östliche Vorgänger haben. Funde aus Rumänien sind derzeit nicht bekannt, könnten jedoch weitere wichtige Hinweise erbringen.

\section{Danksagung}

Unser herzlicher Dank geht an Franz Sauer, Bundesdenkmalamt, der uns die Glocken aus Grab 157, die gezeichneten Befunde und die Fundzeichnungen sowie wertvolle Informationen zukommen ließ. Falko Daim sei gedankt für die Erlaubnis, die Zeichnungen der Glocken aus Grab 354, Goldene Stiege, Mödling und Grab D-56, Zillingtal, publizieren zu dürfen. Einen wichtigen Part spielte auch die Bilddatenbank Montelius, die uns wertvolle Hinweise auf Glockenfunde gab.

\section{Literatur}

BAKAY 1971

K. BAKay, Scythian Rattles in the Carpathian Basin and their Eastern Connections. Amsterdam 1971.

BÖRZSÖNYI 1906

A. BöRzsöNYI, Gyôri temető a régibb középkorból (Frühmittelalterliches Gräberfeld in Győr), Archaeologiai Értesítő 26, 1906, 302-321.

BRUKNER 1968

O. Brukner, Čik-Bačko-Petrovo-Selo: Nekropola iz doba seobe naroda, Arheološki Pregled 10, 1968, 170-173.

ČILINSKÁ 1966

Z. ČIlınská, Slawisch-awarisches Gräberfeld in Nové Zámky. Archaeologica Slovaca Fontes 7, Bratislava 1966.

DAIM 1979

F. DAIM, Awarische Altfunde aus Wien und Niederösterreich, Mitteilungen der Anthropologischen Gesellschaft in Wien 109, 1979, 55-102.

DAIM 1998

F. DAIM, Das awarische Gräberfeld von Zillingtal: Sechs Gräber mit „westlichen“ Gegenständen, Wissenschaftliche Arbeiten aus dem Burgenland 100, Festschrift Hanns Schmid „Zur Landeskunde des Burgenlandes“, Eisenstadt 1998, 97-135.

DAIM, LIPPERT 1984

F. Daim, A. Lippert, Das awarische Gräberfeld von Sommerein am Leithagebirge, NÖ. Studien zur Archäologie der Awaren 1, Wien 1984.

ELLERHORST 1957

W. Ellerhorst, Handbuch der Glockenkunde: Die akustischen, technischen und künstlerischen Grundlagen sowie die Geschichte und Pflege der Glocken. Weingarten 1957.

FETTICH 1965

N. Fеттісн, Das awarenzeitliche Gräberfeld von Pilismarót-Basaharc. Studia Archaeologica 3, Budapest 1965.

FüLŐP 1977

G. FưlőP, A bakonycsernyei avarkori temetô: Le cimetière de l'époque avar à Bakonycsernye. Az István király Múzeum Közleményei Série D, 115, Székesfehérvar - Dunajváros 1977.

GARAM 1972

É. Garam, Avar temetők Andocson (Avar Cemeteries at Andocs), Fólia Archaeologica 23, 1972, 129-182.

GARAM 1975

É. Garam, The Szebény I-III cemetery. In: É. Garam, I. Kovtig, J. Gy. Szaвó, Gy. Töröк, Cemeteries of the Avar Period /567829/ in Hungary, Bd.1: Avar Finds in the Hungarian National Museum. Budapest 1975, 49-120.

GARAM 1995

É. Garam, Cemeteries of the Avar Period /567-829/ in Hungary, Bd. 3: Das awarenzeitliche Gräberfeld von Tiszafüred. Budapest 1995. 


\section{GERE 1998}

L. Gere, Bácskai avar leletek, A Wosinszky Mór Múzeum Évkönyve 20, 1998, 49-115.

HAMPEL 1905

J. Hampel, Alterthümer des Frühen Mittelalters in Ungarn I-III. Braunschweig 1905

HiCKMANN 1956

H. Hickmann, Glocken. In: F. Blume (Hrsg.), Musik in Geschichte und Gegenwart, Bd. 5, Kassel - Basel - London - New York Prag - Stuttgart - Weimar 1956, 267-276.

Hornbostel, SACHS 1914

E. M. Hornbostel, C. SAChs, Systematik der Musikinstrumente: Ein Versuch, Zeitschrift für Ethnologie 46, 1914, 553-590.

IsTVANOVITS, KulcSÁR 1993

E. Istvanovits, V. Kulcsár, Tükrök a császárkori és a kora népvándorlás kori barbár népeknél a Kárpátmedencében, A Herman Ottó Múzeum Évkönyve 30-31/2, 1993, 9-58.

KADA 1905

E. KADA, Gátéri (kunkisszállási) temető a régibb középkorból, Archaeologiai Értesítő 25, 1905, 360-384, 402-407.

KADA 1908

E. KADA, Gátéri (kunkisszállási) temető a régibb középkorból, Archaeologiai Értesítő 28, 1908, 330-339.

KIss 1977

A. KIss, Cemeteries of the Avar Period /567-829/ in Hungary, Bd. 2: Avar Cemeteries in the County Baranya. Budapest 1977.

KIss 1996

A. KIss, Das awarenzeitlich gepidische Gräberfeld von Kölked-Feketekapu A. Monographien zur Frühgeschichte und Mittelalterarchäologie 2, Studien zur Archäologie der Awaren 5, Innsbruck 1996.

Kiss, Somogy 1984

A. Kiss, P. Somogy, Awarische Gräberfelder im Komitat Tolna. Dissertationes Pannonicae Serie III, 2, Budapest 1984.

KÖLTő 1982

L. KöLTő, Avarkori bronztárgyak röntgenemissziós analízise. Somogyi Muzeumok Közleményei 5, 1982, 5-68.

KOVRIG 1963

I. KovRIG, Das awarenzeitliche Gräberfeld von Allatyán. Archaeologia Hungarica Series Nova XL, Budapest 1963.

LÁsZLó 2015

G. LÁszLó, Das awarenzeitliche Gräberfeld in Csákberény-Orondpuszta. Monumenta Avarorum Archaeologica 11, Budapest 2015.

LIPP 1885

V. Lipp, A Keszthely sírmezók. Monumenta Hungariae archaeologica aevi praehistorici, Budapest 1885.

LIPPERT 1969

A. LiPPERT, Das awarenzeitliche Gräberfeld von Zwölfaxing in NÖ. Prähistorische Forschungen 7, Horn 1969.

MADARAS 1995

L. Madaras, The Szeged-Fehértó “A” and "B" Cemeteries: Das awarische Korpus. Avar Corpus Füzetek Beihefte III, Debrecen - Budapest 1995.

MIMO 2011

MIMO, Revision of the Hornbostel-Sachs Classification of Musical Instruments by the MIMO Consortium. http://www.mimointernational.com/documents/Hornbostel\%20Sachs.pdf (letzter Zugriff 28.8.2018)
Mitscha-MäRHEIM 1957

H. Mitscha-Märheim, Der Awarenfriedhof von Leithaprodersdorf. Eisenstadt 1957

MrKobRad 1980

D. MrковRAD, Arheološki nalazi seobe naroda u Jugoslaviji. Fontes Archeologia Jugoslavica 3, Belgrad 1980.

NAĐ 1971

Š. NAĐ (= S. NAGY), Nekropola iz ranog srednjeg veka u ciglani „Polet“ u Vrbasu, РаА војвођанских музеја / Rad Vojvođanskih Muzeja 20, 1971, 187-268.

NAGY 1998

M. NAGY, Awarenzeitliche Gräber im Stadtgebiet von Budapest. Monumenta Avarorum Archaeologica 2, Budapest 1998.

Pany-Kucera, Wiltschke-SchrotTa 2017

D. Pany-Kucera, K. Wiltschke-Schrotta, Die awarische Bevölkerung von Vösendorf/S1, Annalen des Naturhistorischen Museums in Wien, Serie A für Mineralogie und Petrographie, Geologie und Paläontologie, Anthropologie und Prähistorie 119, 2017, 5-31.

Pomberger 2018

B. M. Pomberger, Roman Bells in Central Europe: Typologies and Discoveries. Online Manuskript, https://www.academia. edu/36120431/Roman_Bells_in_Central_Europe_Typologies_ and_Discoveries (letzter Zugriff 29.8.2018).

Pomberger, Stadler 2018

B. M. Pomberger, P. Stadler, Der Klang der Schellen: Schellenfunde aus dem awarischen Gräberfeld von Vösendorf-Laxenburgerstraße, Österreich, Študijné zvesti Archeologického ústavu SAV Nitra 63, 2018, 125-146.

ROSNER 1999

G. Rosner, Das awarenzeitliche Gräberfeld in Szekszárd-Bogyiszlói Straße. Monumenta Avarorum Archaeologica 3, Budapest 1999.

SAUER 2007

F. SAUER, Das awarische Gräberfeld. Die archäologischen Grabungen auf der Trasse der S1: Fundstelle Vösendorf, Laxenburgerstraße. Bad Vöslau 2007.

Sós 1961

A. Sós, Újabb avarkori leletek Csepel szigetról, Archaeologiai Értesítő 88, 1961, 32-51.

Sós 1967

Á. Sós, A dunaszekcsői avarkori temető, Fólia Archaeologica 18, 1967, 91-122.

STADLER 2005

P. STAdler, Quantitative Studien zur Archäologie der Awaren I. Mitteilungen der Prähistorischen Kommission 60, Wien 2005.

STADLER 2018

P. Stadler, Bilddatenbank Montelius: Deszk-O. nach B. Kürti; Mödling-Goldene Stiege nach F. Daim; Szegvár-Oromdúlö nach G. Lőrinczy; Zillingtal nach F. Daim; Budakalász nach T. Vida, alle unpubliziert.

STREINZ 1978

L. Streinz, Wien 11 - Csokorgasse, Fundberichte aus Österreich 16/1977, 1978, 475-531.

Tӧвӧк 1994

G. TöRÖк, Das awarenzeitliche Gräberfeld von Solymár. Debrecen - Budapest 1994

UENZE 1966

S. Uenze, Die Schnallen mit Riemenschlaufen aus dem 6. und 7. Jahrhundert, Bayerische Vorgeschichtsblätter 31, 1966, 142-181. 
VILLING 2002

A. VILLing, For whom did the bell toll in ancient Greece? Annual of the British School at Athens 97, 2002, 232-296.

VINSKI 1958

Z. VINSKI, O nalazima 6. i 7. stoljeća u Jugoslaviji s posebnim obzirom na arheološku ostavštinu iz vremena prvog avarskoga kaganata, Opuscula Archaeologica 3, 1958, Zagreb, 13-55.

Beate Maria Pomberger Institut für Urgeschichte und Historische Archäologie Universität Wien Franz Klein-Gasse 1 1190 Wien

Österreich beate.maria.pomberger@univie.ac.at (iD) orcid: 0000-0002-3366-0924

Peter Stadler Prähistorische Abteilung Naturbistorisches Museum Wien Burgring 7 1010 Wien Österreich peter.stadler@univie.ac.at iD orcid: 0000-0003-4000-3778 
